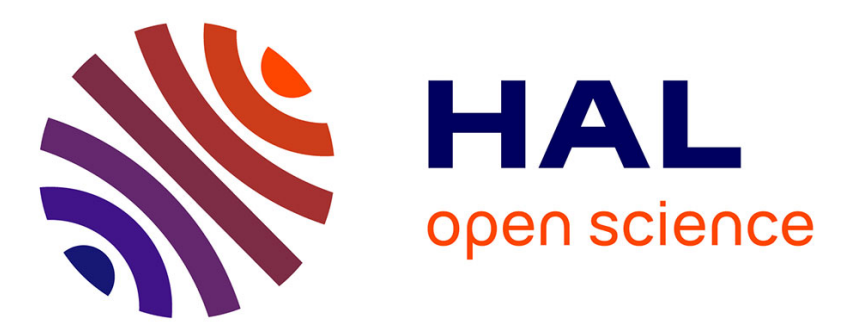

\title{
Density functional theory simulations of complex catalytic materials in reactive environments: beyond the ideal surface at low coverage.
}

Céline Chizallet, Pascal Raybaud

\section{- To cite this version:}

Céline Chizallet, Pascal Raybaud. Density functional theory simulations of complex catalytic materials in reactive environments : beyond the ideal surface at low coverage.. Catalysis Science \& Technology, 2014, 4 (9), pp.2797-2813. 10.1039/c3cy00965c . hal-01069690

\section{HAL Id: hal-01069690 \\ https://hal-ifp.archives-ouvertes.fr/hal-01069690}

Submitted on 5 Dec 2014

HAL is a multi-disciplinary open access archive for the deposit and dissemination of scientific research documents, whether they are published or not. The documents may come from teaching and research institutions in France or abroad, or from public or private research centers.
L'archive ouverte pluridisciplinaire $\mathbf{H A L}$, est destinée au dépôt et à la diffusion de documents scientifiques de niveau recherche, publiés ou non, émanant des établissements d'enseignement et de recherche français ou étrangers, des laboratoires publics ou privés. 


\section{Catalysis

Cite this: Catal. Sci. Technol., 2014, 4,2797

Received 25th November 2013, Accepted 14th May 2014

DOI: $10.1039 /$ c3cy00965c

www.rsc.org/catalysis

\section{Density functional theory simulations of complex catalytic materials in reactive environments: beyond the ideal surface at low coverage}

\author{
Céline Chizallet and Pascal Raybaud*
}

Most efficient heterogeneous catalysts used industrially are generally very complex systems. Far away from perfect crystallinity and well-defined oriented surfaces at low coverage, they involve structural disorder, heterogeneous site distribution with variable coordination and structural dependence upon the chemical environment. Unravelling their atomic-scale structures and understanding their roles in the catalytic reaction are not easy tasks, as the respective contributions of each type of site to the spectroscopic or catalytic responses are generally convoluted. Computational chemistry is of great help to address these issues. In the present perspective review, we highlight two relevant systems involved in numerous industrial applications: the amorphous silica alumina support; and subnanometric platinum clusters, possibly doped with tin and/or indium, supported on $\gamma-\mathrm{Al}_{2} \mathrm{O}_{3}$. The structural complexity is inherent to the amorphous nature of an oxide support on the one hand, and to the ultra-dispersed form of a mono- and multi-metallic catalyst on the other hand. In each case, Density Functional Theory (DFT) calculation was used to provide an original structure for active sites and to reveal how the corresponding multi-step reactions are influenced. Moreover, we highlight how theoretical studies including coverage effects on complex systems, induced by $(T, P)$ reaction conditions, offer enriched perspectives with respect to studies on ideal surfaces at low coverage.
IFP Energies nouvelles, Direction Catalyse et Séparation, Rond-point de l'échangeur de Solaize, BP3, 69360 Solaize, France. E-mail: pascal.raybaud@ifpen.fr, celine.chizallet@ifpen.fr; Fax: +334377020 66; Tel: +33437702320

\section{Introduction}

Since the 19th century, when "catalysis" was given a definition by J. J. Berzelius, heterogeneous catalysis was at the origin of significant societal advances, materialized by the set-up

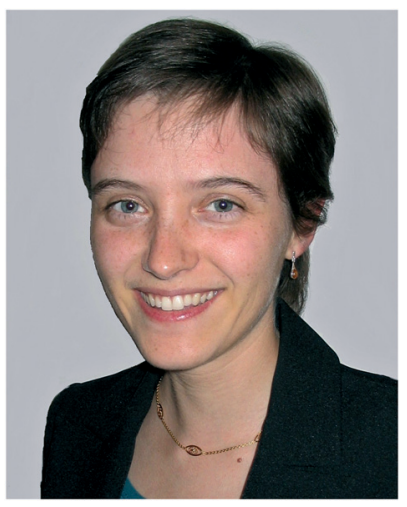

Céline Chizallet

Céline Chizallet graduated from Ecole Normale Supérieure (Paris) and Paris 6 University (MSc in 2002). She obtained the "Agrégation de Chimie" in 2003 and a PhD in Inorganic Chemistry in 2006 under the guidance of Profs. M. Che, G. Costentin and H. Lauron-Pernot, in collaboration with Philippe Sautet (ENS-Lyon). She joined the team of H. Toulhoat and P. Raybaud at IFP Energies nouvelles in 2006. She currently holds a researcher position in the Catalysis and Separation Division. Her research interest deals with computational catalysis, in particular surfaces of oxides and supported metals. She has co-authored more than 40 publications, one book chapter and one patent.

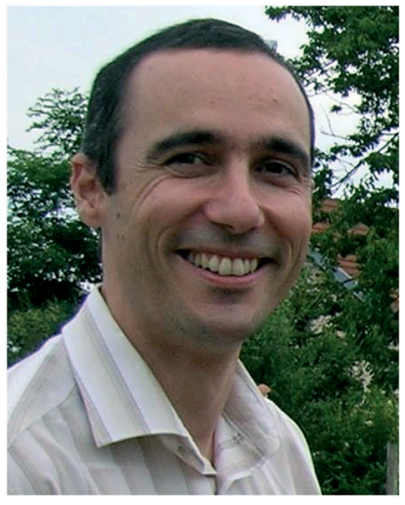

Pascal Raybaud
Pascal Raybaud obtained a PhD in chemistry jointly from Technical University of Vienna (Austria), Paris 6 University (France) and IFP Energies nouvelles in 1998, under the guidance of Profs. J. Hafner, B. Silvi and H. Toulhoat. His research works combined experimental and computational chemistry approaches applied to refining catalysts, hydrogen storage and photocatalytic materials. In 2010, he was awarded the Prize of the Catalysis Division (French Chemical Society). He has co-authored more than 90 publications, 12 patents, and is co-editor of the book "Catalysis by Transition Metal Sulphides - From Molecular Theory to Industrial Application" (Editions Technip, France, 2013). 
of major catalytic processes, such as the synthesis of ammonia, ${ }^{1,2}$ hydrotreatment ${ }^{3}$ Fischer-Tropsch synthesis, ${ }^{4-6}$ catalytic cracking ${ }^{7}$ and reforming, ${ }^{8,9}$ and automotive exhaust treatment ${ }^{10-14}$ to name a few. Advanced rationalization studies of catalytic reactivity and surface reactions were undertaken very early, some of them being awarded Nobel prizes, as P. Sabatier ${ }^{15}$ (in 1912), I. Langmuir ${ }^{16}$ (in 1932) and, more recently, G. Ertl (in 2007). ${ }^{17}$ One may, however, admit that earlier most efficient industrial heterogeneous catalysts, such as those used in refining plants, were discovered empirically, thanks to a combination of sharp chemical intuition and strong opportunism. For instance, the promoting effect of Co in $\mathrm{MoS}_{2}$ systems, widely used nowadays in hydrotreating processes, was discovered around WWII only after a large number of trial-and-error experiments. ${ }^{18,19}$ Similarly, reforming catalysts have been the subject of continuous empirical improvements since WWII, involving various types of dopants (Sn, Re...) added either on the metallic phase (Pt) or on the alumina support, the role of which, however, remains under debate. ${ }^{8,9,20}$ Thus, the composition and structure of the industrial catalysts (active phase and support) are generally very complex. Current applied research integrates advanced tools for the discovery of new, efficient active phases, ${ }^{21-23}$ which usually brings additional components to the original formulations of heterogeneous catalysts.

However, accurate control of the catalytic performance requires advanced knowledge of the structure of the numerous active sites and of the origin of their catalytic properties, at the atomic scale. This is not an easy task from the experimental point of view, as the respective contributions of each type of site to the spectroscopic or catalytic response are generally convoluted. One may choose two rational approaches to unravel this issue. The first one consists of the elaboration of ideal model catalytic systems, exhibiting a limited variety of sites of controlled coordination, taking part in a welldefined crystalline network, to isolate their respective structure and implication in catalytic reactions. These model systems can be cleaved single crystals or thin films obtained by surface science techniques, ${ }^{24-26}$ or particles with controlled morphology and narrow size distributions ${ }^{27-30}$ for example. The second approach is based on the development of advanced analytical methods, ${ }^{29,31-34}$ possibly designed for in situ and operando experiments, ${ }^{35,36}$ and of innovative catalytic procedures and reactors..$^{22,37,38}$ of course, both approaches can be combined, and have led to significant achievements in the understanding of metallic and oxide surfaces in particular. ${ }^{39}$

Computational chemistry is a precious and complementary approach that can provide a better description and understanding of heterogeneous catalytic active sites at the atomic scale. Thanks to the development of Density Functional Theory (DFT) elaborated by Hohenberg and Kohn (one of the Nobel Prize winners in Chemistry 1998), ${ }^{40}$ it is now possible to apply quantum chemistry for the simulation of simple catalytic systems, such as perfectly crystalline zeolites and ideal metal surfaces. ${ }^{41,42}$ Due to high computational requirements, the simulation of more complex catalytic systems as a whole remains, however, not trivial.

Most commonly used types of models for heterogeneous catalysts have been detailed in previous perspectives. ${ }^{43,44}$ In brief, the system can be modelled either by clusters of finite numbers of atoms or by ideal infinite surfaces within periodic boundary conditions. The cluster approach consists of the simulation of a piece of a particle (representing the active phase) from ten to several tens of atoms. In the spirit of hybrid schemes developed for the simulation of macromolecules by Warshel, Levitt and Karplus (the Nobel Prizes in Chemistry 2013), in particular biomacromolecules, ${ }^{45}$ embedding species can be added in the surrounding to describe, at a lower level of theory, the remaining part of the catalyst particle. ${ }^{46,47}$ The periodic approach consists of the simulation of an elementary cell, containing around several tens to several hundreds of atoms. The cell is periodically replicated over three (sometimes two) directions in space for the simulation of a crystal, or of an infinite surface if a vacuum layer is introduced.

By essence, a model of the surface is aimed at so that quantum calculations are preferentially compared to experiments performed on model systems. When dealing with periodic approaches, ideal cleaved surfaces of catalytic materials or ideal bulk structures of microporous materials are generally considered as models. This is the case, for example, for simulations of zeolites ${ }^{41,48}$ or metallic surfaces. ${ }^{43}$ In the latter systems, low index crystallographic orientations depending on the metal crystal symmetry are chosen as relevant for metallic active sites exposed on the particles. ${ }^{41,49,50}$ For FCC metals, the most stable (111) terrace led to the most important amount of work. The appropriate choice of specific cleavage orientations (generally with high Miller indices) also enable the simulation of periodic defects such as steps. ${ }^{49,51}$ For the study of chemical reactivity at such metallic surfaces, the most convenient way is to start from a bare surface, and to consider low and constant reactant coverage, so as to identify the intrinsic effect of the metal nature and local structure on the reaction energies and activation barriers, and possibly deduce some "universal" trends in catalysis. ${ }^{50}$

During the last decade, a great number of theoretical studies have been published in this spirit. This ideal surface approach at low coverage is expected to be powerful and relevant when the chemical state of the catalytically active phase is weakly perturbed by the chemical environment: coverage effects, support effects, change of surface chemical composition, etc. Regarding the degree of complexity reached by the real catalytic systems (either at the industrial scale or the laboratory scale), it is often mandatory to go beyond the ideal surface approach at low coverage. This is particularly true when defects cannot be described by specific cleavage orientations of the bulk materials, such as for low-coordinated sites of nano-aggregates, extra-framework species or vacancies, ${ }^{52-62}$ and when they dominate the surface reactivity of solids. It is also mandatory to address the complexity of 
the system for supported catalysts when support effects are suspected to influence directly or indirectly the reactivity. ${ }^{63-65}$ This is the case in bifunctional catalysts such as hydroisomerization or hydrocracking where a hydrogenation function is brought by a metallic phase (reduced or sulfided) and a cracking or isomerizing one is brought by the acidic support, such as a crystalline zeolite or an amorphous silica alumina (ASA). ${ }^{3,7,66}$ In addition, an indirect support effect occurs when the size of the active nanoparticles becomes sub-nanometric such as in reforming catalysts. ${ }^{9}$ Their electronic and structural properties are expected to be modified by the support. Finally, the ideal surface model at low coverage is no longer relevant when the reaction conditions modify the chemical state of the catalyst. Several well-known examples illustrate that a metallic surface does not remain purely metallic and tends to become either oxidized under oxygen partial pressure, ${ }^{67,68}$ or carburized under carbon chemical potential. ${ }^{69-72}$ Most oxide surfaces usually become hydroxylated when contacted with moisture, which obviously influences their Brønsted/Lewis acidities. ${ }^{53,73-78}$

This complexity represents a double challenge for current and future atomic scale simulation: firstly, one needs to include a sufficiently large number of atoms, arranged in a rational manner - not arbitrarily - to render the variety of surface sites such as Lewis and Brønsted acido-basic sites, defects, etc., which is limited by computational resources and code performance. Secondly, one has to undertake a rational approach to propose a relevant model for a complex system working under given reaction conditions, which modifies the chemical state of the surface.

As methodological aspects and challenges of quantum calculations for heterogeneous catalysis have been the object of previous perspectives, ${ }^{43,44}$ we focus here on the need to take into account the complexity in the molecular models to reach chemical relevance for current or future industrial catalysts. We highlight first-principles studies performed in our group, which have recently addressed this high degree of complexity of the catalytic system under the following reaction conditions:

- amorphization of oxide surfaces on the one hand, with the particular case of amorphous silica alumina (ASA),

- ultra-dispersed mono- and multi-metallic catalysts, with the example of subnanometric platinum clusters, possibly doped with tin and/or indium, supported on $\gamma-\mathrm{Al}_{2} \mathrm{O}_{3}$.

Both aspects will be discussed in close conjunction with the effect of the surrounding environment: the temperature and partial pressures of the main reactants, which directly influence the coverage effects.

The two systems addressed here are of paramount importance in industrial catalysis. ASA is the acidic support of catalysts involved in hydrocracking, ${ }^{7,79}$ and is also used in the field of biomass conversion ${ }^{80,81}$ due to its mild acidic properties. Ultra-dispersed platinum-based catalysts supported on $\gamma$-alumina are involved in dehydrogenation and catalytic reforming processes, inter alia. ${ }^{9}$ The rational and molecularscale approach has led to the proposal of original surface sites which revisit some experimental findings but also open avenues for future experiments. The impact of ambient atmosphere and reactive medium is taken into account thanks to a thermodynamic approach. The structural complexity of these systems is also at the origin of an enriched catalytic behaviour for multi-step reactions. We will show how DFT calculations can also help in this field. Through these two examples, we will propose some challenges and perspectives in the integration of chemical complexity in the simulation of heterogeneous catalysis.

\section{General methods}

The search for more and more accuracy for a reasonable computational cost is a motivation in our field. ${ }^{43}$ We use state-of-the-art methods for the elaboration of models of heterogeneous catalysts. Most calculations reported in the present perspective were performed in the framework of Density Functional Theory, using a periodic plane-wave method as implemented in the Vienna $a b$ initio Simulation Package (VASP). ${ }^{82,83}$ The exchange-correlation functional was treated within the generalized gradient approximation (GGA) as parameterized by Perdew and Wang (PW91) ${ }^{84}$ or by Perdew, Burke and Ernzerhof (PBE). ${ }^{85}$ The projected augmented wave (PAW) method ${ }^{86}$ was used to describe the interactionss of core-electrons, with energy cutoffs between 400 and $500 \mathrm{eV}$. Dipolar correction was applied to account for the arbitrary interaction between asymmetric - and thus polar - slabs. In some cases, molecular dynamics calculations were undertaken to obtain more stable systems, likely to be a more relevant model for the complex systems under study. To account for reactive environment (temperature, and partial pressure of $\mathrm{H}_{2} \mathrm{O}, \mathrm{H}_{2}$, hydrocarbon), we undertook thermodynamic calculations with the assumption that all gaseous species behave like ideal gases. For further details, the reader is invited to read the respective papers. ${ }^{20,87,88}$

Both systems presented in this perspective share a common starting "ingredient", which is the alumina support model developed previously by Digne et al. ${ }^{73,74}$ on the basis of the $\gamma-\mathrm{Al}_{2} \mathrm{O}_{3}$ bulk model established by Krokidis et al. ${ }^{89}$ The (100) and (110) surface orientations represent about $90 \%$ of the total surface area of the particles. The (100) orientation is the less reactive (in particular the less hydrophilic one), whereas the (110) surface remains hydroxylated up to high temperatures/low water partial pressures. ${ }^{77}$ These surfaces can possibly be chlorinated to promote their acidity. A chlorinated model has also been established by Digne et al. ${ }^{90}$ All these surface models were the basis for the simulation of more complex systems, as shown below.

\section{Surface models for amorphous silica alumina}

Amorphous silica aluminas (ASAs) are composed of variable amounts of silica $\left(\mathrm{SiO}_{2}\right)$, alumina $\left(\mathrm{Al}_{2} \mathrm{O}_{3}\right)$ and water $\left(\mathrm{H}_{2} \mathrm{O}\right)$, and are widely used for their acidic character. ${ }^{7}$ Zeolites, 
which also belong to the aluminosilicate family, are also widely used in catalysis. Being well-defined crystalline materials, the relationship between their structure and acidity has been characterized and studied extensively for some decades. ${ }^{91-94}$ By contrast, the lack of long-range ordering in ASA hampers systematic characterization of the local environment around each cationic species. However, these materials are regaining interest for industrial applications, in particular for the enhancement of the selectivity in middle distillates in hydrocracking reactions, ${ }^{7,95}$ and for biomass conversion. ${ }^{80,81}$ From a fundamental point of view, the determination and the characterization of the acid sites of ASAs remain challenging open questions. Structural hypotheses are not unanimous between research groups. ${ }^{96-101}$ New insights have recently been acquired through DFT calculations, ${ }^{87,102-104}$ leading to a surface model for silicated alumina, which accounts for the presence of original surface sites at the origin of mild acidity. Note that, to the best of our knowledge, despite significant effort on the simulation of bulk aluminosilicate glasses for geology, ${ }^{105,106}$ simulation studies of the surface of ASA have not been undertaken before, except for some earlier attempts to choose "local" models, as aluminosilsesquioxanes. ${ }^{107,108}$

\subsection{Grafting of silica derivates on alumina}

ASA samples can be synthesized by very different methods, ${ }^{109}$ in particular by deposition of organosilanes $\mathrm{Si}(\mathrm{OR})_{4}$ on $\gamma-\mathrm{Al}_{2} \mathrm{O}_{3}$. This method yields silicated alumina with satisfactory control of the amount of silica deposited. ${ }^{110}$ An exchange reaction is expected to take place with the $\mathrm{OH}$ groups of alumina $^{111-113}$ followed by hydrolysis. The overall reaction is thus formally equivalent to silicic acid $\mathrm{Si}(\mathrm{OH})_{4}$ exchange with the $\gamma-\mathrm{Al}_{2} \mathrm{O}_{3}$ hydroxyls: this general reaction was modelled by DFT calculations.

We started with the $\gamma-\mathrm{Al}_{2} \mathrm{O}_{3}$ alumina model obtained previously by Digne et al. ${ }^{73,74}$ (see Section 1). The (100) surface of alumina appeared to be the most interesting in terms of amorphization. ${ }^{87}$ For silicic acid coverage $\theta_{\mathrm{Si}}=0.5 \mathrm{~nm}^{-2}$, the preferred exchanged configurations led to the competitive bidentate and monodentate structures illustrated in Fig. 1-(a) (top), obtained by exchange mainly with $\mu_{1}-\mathrm{OH}$, consistently with infra-red experiments. ${ }^{113}$

Additional silicic acid molecules $\left(\theta_{\mathrm{Si}}=1.1 \mathrm{~nm}^{-2}\right)$ condense with the previously grafted species (Fig. 1-(a), bottom), rather than graft onto other alumina $\mathrm{OH}$ groups. The condensation reaction energies (ca. $-30-40 \mathrm{~kJ} \mathrm{~mol}^{-1}$ ) show that increasing the silicic acid content in a wet environment leads to the growth of silica particles in contact with $\gamma-\mathrm{Al}_{2} \mathrm{O}_{3}$ (100) by only a few anchoring points (Fig. 1-(b)). Thus, in the absence of any thermal treatment, no intimate interaction between silica and $\gamma-\mathrm{Al}_{2} \mathrm{O}_{3}$ can be reported on the (100) $\gamma-\mathrm{Al}_{2} \mathrm{O}_{3}$ surface.

The effects of thermal treatment were deduced from simulation starting from an epitaxially deposited silica film (with $\theta_{\mathrm{Si}}=6.4 \mathrm{Si} \mathrm{nm}^{-2}$ ) over the $\gamma-\mathrm{Al}_{2} \mathrm{O}_{3}$ dehydrated surface, submitted to a simulated annealing sequence combining DFT and force-field molecular dynamics. The formation of an amorphous phase, and the mixing of silica and alumina were observed (Fig. 2-(a)).

Aluminium atoms migrated from the alumina phase to a mixed ASA phase. Released from an octahedral position in pure alumina, they finally exhibit tetrahedral and pentahedral coordination, which is in line with experimental findings from ${ }^{27} \mathrm{Al} \mathrm{NMR:}{ }^{27}$ the $\mathrm{Al}_{\mathrm{IV}} / \mathrm{Al}_{\mathrm{VI}}$ ratio is higher in ASA than in $\gamma-\mathrm{Al}_{2} \mathrm{O}_{3},{ }^{98,114}$ and $\mathrm{Al}_{\mathrm{V}}$ exists in ASA. ${ }^{114,115}$ The crucial impact of thermal treatment for the synthesis of an ASA phase is thus molecularly demonstrated. The surface obtained exhibits some original $\mathrm{Al}_{\mathrm{IV}}$ and $\mathrm{Al}_{\mathrm{V}}$ likely to behave as Lewis acids, but the generation of Brønsted acid sites requires $\mathrm{OH}$ groups.

The surface state of ASA was thus determined as a function of the temperature and partial water pressure (Fig. 2-(b)), by simulating the successive adsorption of water molecules. Silanols are preferentially generated over $\mathrm{Al}-\mathrm{OH}$ groups. (a)

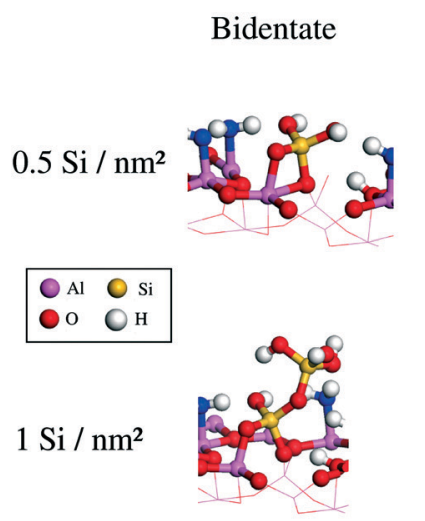

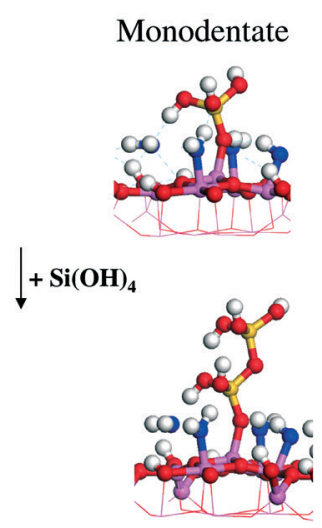

(b)

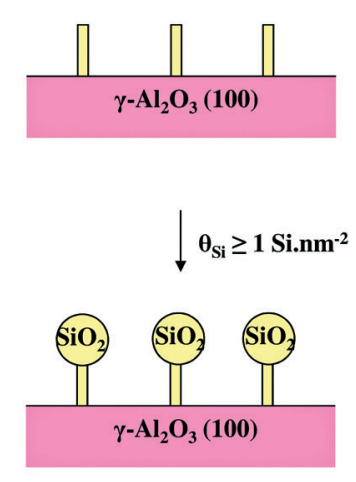

Fig. 1 (a) Preferred exchanged structures, calculated by DFT, of $\mathrm{Si}(\mathrm{OH})_{4}$ on the hydrated $\gamma-\mathrm{Al}_{2} \mathrm{O}_{3}(100)$ surface, for monodentate and bidentate configurations, and for $\theta_{\mathrm{Si}}=0.5$ and $1 \mathrm{Si} \mathrm{nm}^{-2}$. (b) Diagram illustrating the surface state after silicic acid deposition, without any thermal treatment. Adapted with permission from ref. 87. Copyright 2009, Wiley and Sons. 
(a)
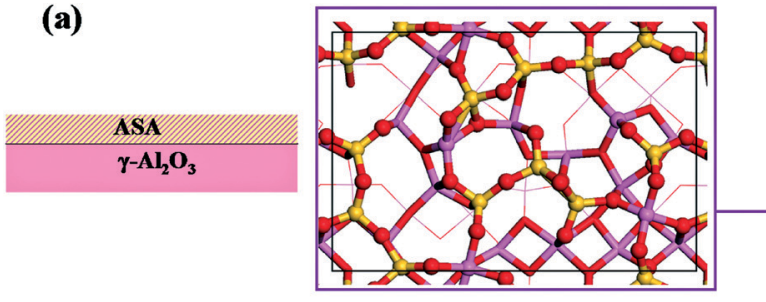

(b)

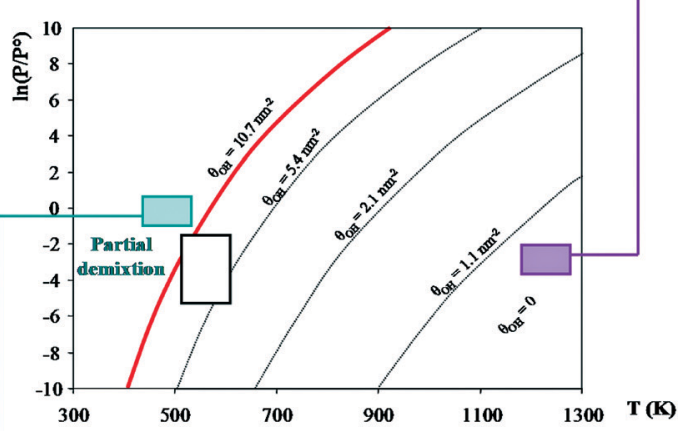

(c)

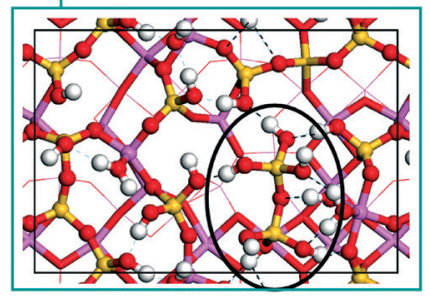

Fig. 2 (a) Top view of the fully dehydrated ASA surface model. Sideview scheme of the mixed phase deposited on alumina. (b) Thermodynamic diagram depicting the $\mathrm{OH}$ content as a function of the temperature and the partial water pressure. The black rectangular zone corresponds to typical conditions for reactivity applications. (c) Top view of the ASA surface model at $\theta_{\mathrm{OH}}=10.7 \mathrm{~nm}^{-2}$, where the ellipse highlights the silicic acid dimer demixed from ASA upon successive water molecule adsorption, which leads to partial segregation of silica as shown in the scheme. Adapted with permission from ref. 87. Copyright 2009, Wiley and Sons.

For high water contents (Fig. 2-(c)), silicic oligomers demix from the ASA phase. These types of oligomer are expected to segregate so that part of the mixed ASA phase is lost. In particular, calculations predict a systematic trend of demixing at room temperature (unless some kinetic limitations occur), illustrating again the most important role of thermal treatment in the stabilization of a mixed aluminosilicic phase.

\subsection{Hydroxyl groups present on the ASA surface models}

For typical analytical and reactivity conditions, surface models exhibiting 5.4 and $6.4 \mathrm{OH} \mathrm{nm}^{-2}$ (black rectangle in Fig. 2-(b)) are representative of the real surface state. On these surface models (Fig. 3-(a) and (b)), various species are identified: $\mathrm{Al}_{\mathrm{IV}}$ and $\mathrm{Al}_{\mathrm{V}}$ atoms, as well as several kinds of hydroxyls. In particular, one bridging $\mathrm{Si}-(\mathrm{OH})-\mathrm{Al}$ site (Fig. 3-(c)) is present. Silanol bonded to aluminium atoms $\left(\mathrm{Al}_{\mathrm{VI}}\right.$ and/or $\left.\mathrm{Al}_{\mathrm{V}}\right)$ via structural Si-O-Al bridges are found (Fig. 3-(d)). We called these groups silanol-Al.

Several silanols in interaction through space (no Al-O covalent bond) with one acceptor $\mathrm{Al}_{\mathrm{IV}}$ or $\mathrm{Al}_{\mathrm{V}}$ atom are also present (Fig. 3-(e)). These we called Pseudo-Bridging Silanols (PBS), ${ }^{87,102,103}$ in particular PBS-Al, when $\mathrm{Al}$ acts as the "acceptor" atom. In some cases, a silicon atom may also play the role of the acceptor (Fig. 3-(f)), as seen with the so-called PBS-Si group. Note that since then, PBS-Al-like sites have been suspected on silicated alumina from experiments. ${ }^{116}$

This variety of $\mathrm{OH}$ group environments as suggested by the model explains the complexity of the infra-red spectra of ASA. The vibration frequencies of OH groups on the ASA surface model were indeed calculated and compared to experiments (Fig. 4). ${ }^{103}$ The $\mathrm{Si}-\mathrm{OH}$ frequency, calculated and observed near $3740 \mathrm{~cm}^{-1}$ in silica ${ }^{117}$ is lowered when the silanol is in close proximity (silanol-Al and PBS-Al) to an $\mathrm{Al}$ atom. The difficult observation of zeolite-like bridging $\mathrm{OH}$ groups on the ASA is also explained by their lower thermal stability than in zeolites, as well as the dominant contribution of hydrogen-bond donor $\mathrm{OH}$ groups in the same spectral region. This study has a double interest: together with the assignment of the FTIR spectra of ASA samples, a validation of the theoretical model is obtained.

\subsection{Acidity of $\mathrm{OH}$ groups on ASA: on the dominant role of the stability of the conjugated base}

Thanks to this model, the independent behaviour of each site can be inferred with regard to basic probe molecules. Zeolitelike bridging $\mathrm{Si}-(\mathrm{OH})-\mathrm{Al}$ groups, similar to those of protonic zeolites, are often referred to as the most acidic sites of ASA, ${ }^{99,118-120}$ but their existence is questioned by other authors ${ }^{96,97}$ due to the absence in the ASA IR spectra of the typical well-defined $\mathrm{O}-\mathrm{H}$ bands observed in zeolites. Our DFT calculations show that they can exist on the ASA surface, ${ }^{87}$ even if the coordination number of their aluminium atom is not systematically equal to four. Silanols bonded to lowcoordinated aluminium atoms by a $\mathrm{Si}-\mathrm{O}-\mathrm{Al}$ bridge were presented as the most acidic Brønsted sites by Crépeau and co-workers, ${ }^{98}$ depending on the number and coordination of $\mathrm{Al}$. These sites are related to the silanol-Al proposed within the DFT model.

The adsorption of probe molecules of various basicity was then simulated ${ }^{102}$ on the four sites depicted in Fig. 3: CO, pyridine, lutidine and ammonia. All nitrogenated probe molecules are converted in their protonated conjugate acid on the bridging $\mathrm{Si}-(\mathrm{OH})-\mathrm{Al}$ group, with adsorption energies lower than protonic zeolites. Conversely, silanol-Al was unable to protonate any of the molecules under study. PBS-Al exhibits more interesting chemical behaviour, as illustrated in Fig. 5: probe molecule adsorption induces a tilt of the oxygen of PBS-Al in the direction of the aluminium atom. This phenomenon is reinforced by increasing the probe molecule basicity, with protonation of lutidine and ammonia. This is accompanied by the formation of a new Al-O bond, 
(a)

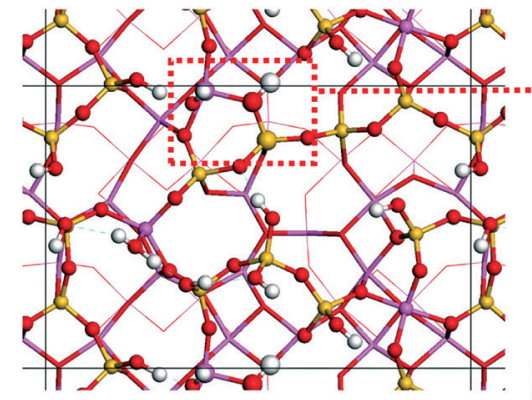

(b)
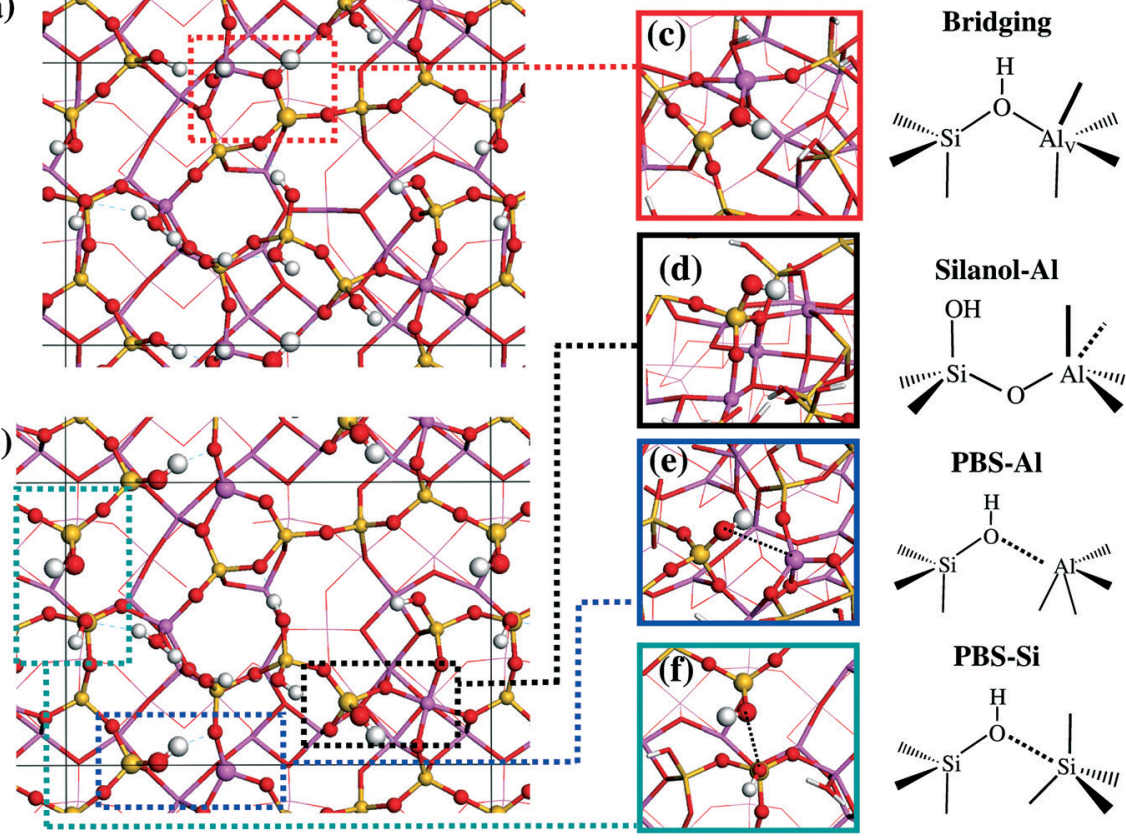

Fig. 3 Top view of the ASA surface model for (a) $\theta_{\mathrm{OH}}=6.4 \mathrm{OH} \mathrm{nm}{ }^{-2}$, (b) $\theta_{\mathrm{OH}}=5.4 \mathrm{OH} \mathrm{nm}^{-2}$; (c) bridging OH group; (d) example of silanol-Al group; (e) example of PBS-Al (PBS: Pseudo-Bridging Silanol); (f) example of PBS-Si.

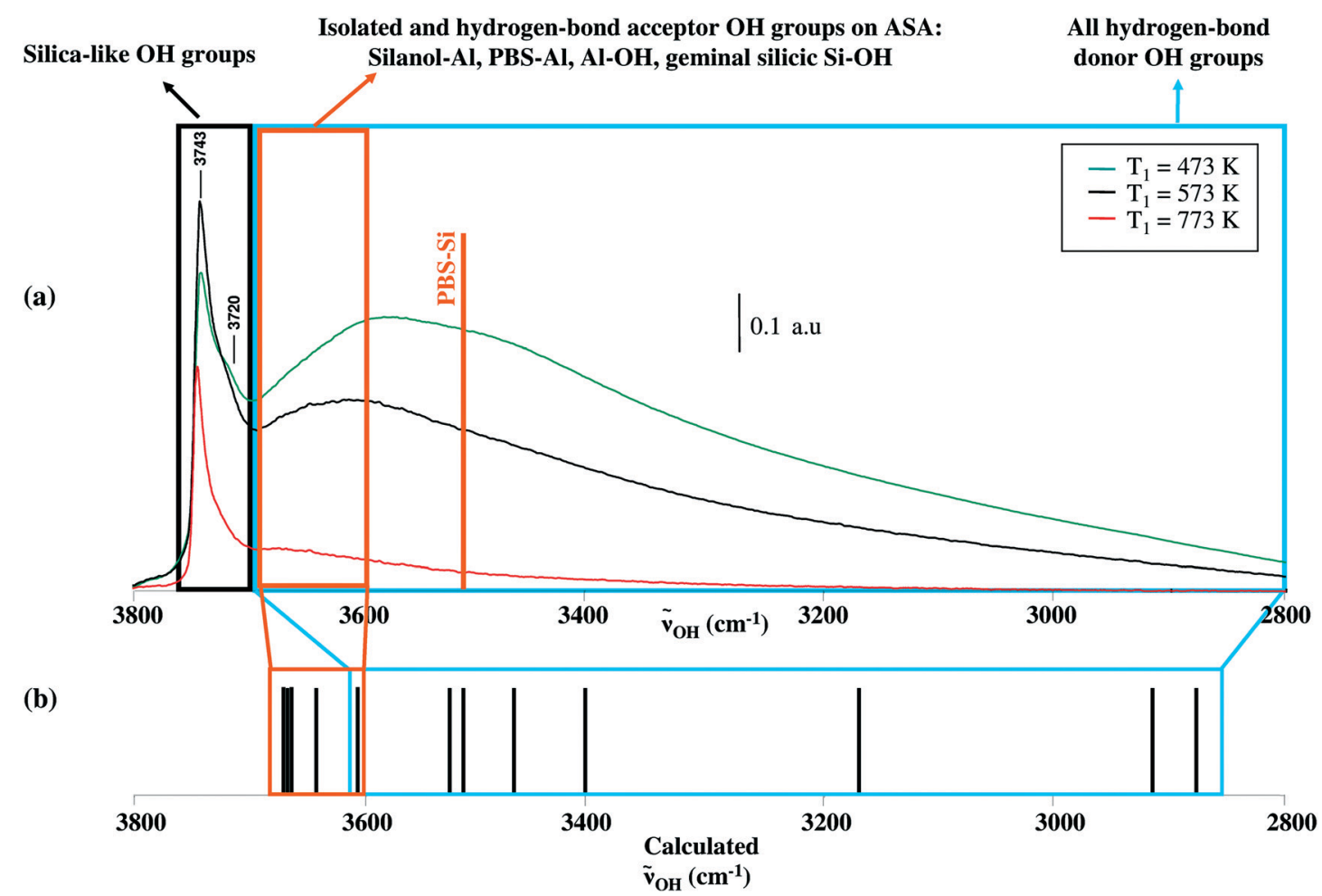

Fig. 4 (a) Experimental infrared spectra of ASA, in the $\mathrm{O}-\mathrm{H}$ stretching zone, for the ASA sample evacuated at 473, 573, or $773 \mathrm{~K}$. The assignment proposed is based on the computational results. (b) Calculated $\mathrm{O}-\mathrm{H}$ vibration frequencies for the various sites present on the ASA model. Adapted with permission from ref. 103. Copyright 2011, Elsevier.

increasing the coordination of the acceptor $\mathrm{Al}$ atom from four to five. This phenomenon relates to the proposal put forward by Trombetta et al. ${ }^{96}$ based on experiments of nitrogenated molecules on ASA monitored by FTIR. More surprisingly, the same kind of behaviour was found for PBS-Si, with the formation of $\mathrm{Si}_{\mathrm{v}}$. Consequently, together with bridging $\mathrm{Si}-(\mathrm{OH})-\mathrm{Al}$ groups, PBS-Si appears to be one of the most acidic Brønsted sites on the ASA surface, with a higher 


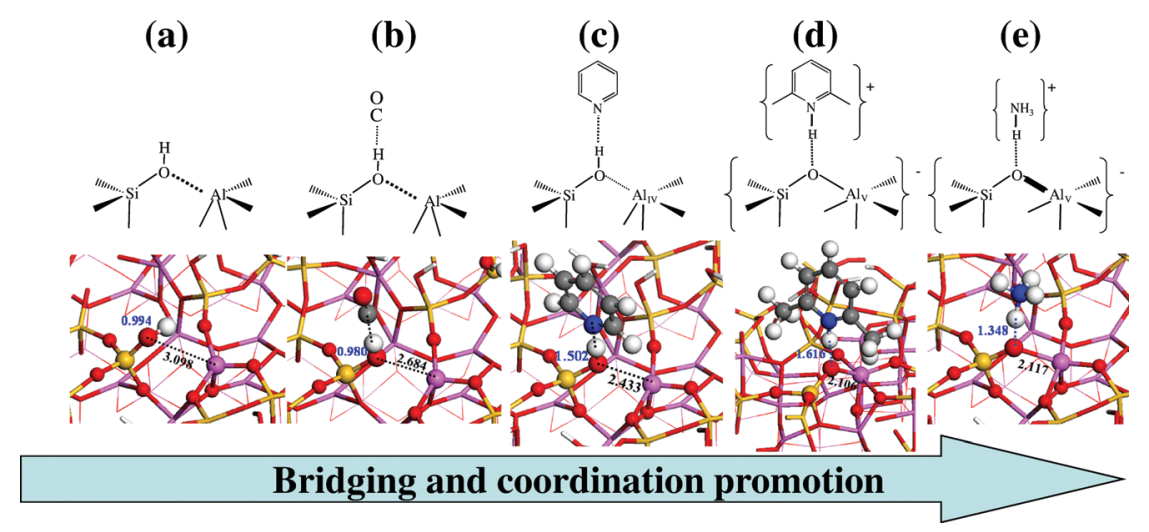

Fig. 5 Behaviour of aluminic pseudo-bridging silanols (PBS-Al) towards basic probe molecules: (a) no probe molecule, (b) CO, (c) pyridine, (d) lutidine, (e) ammonia. $\mathrm{O} \cdots \mathrm{H}$ distances and $\mathrm{O}-\mathrm{H}$ bond lengths $(\AA \AA)$ are given in blue, $\mathrm{O} \cdots \mathrm{M}$ distances and $\mathrm{O}-\mathrm{M}$ bond lengths (Å) in black. Adapted with permission from ref. 102. Copyright 2010, Wiley and Sons.

protonating ability than PBS-Al (pyridinium ion being generated on PBS-Si).

A more detailed analysis was performed in the case of lutidine adsorption, on all sites of the ASA surface model. ${ }^{103}$ As with PBS and bridging OH- groups, water molecules adsorbed on aluminium atoms exhibit interesting proton transfer ability. This is consistent with previous experimental proposals. ${ }^{100,121}$ In a general manner, we showed that the main factor governing the proton transfer ability of acidic sites of ASA is the stabilization of the conjugated base (of the acidic site), either upon formation of $\mathrm{Al}-\mathrm{O}$ or $\mathrm{Si}-\mathrm{O}$ bonds, or by cascade proton transfer, ${ }^{103}$ as explained in Fig. 6. In addition, the properties of the modelled ASA OH groups were compared to that of an ideal bridging $\mathrm{OH}$ group within mordenite. The lower Brønsted acidity of ASA compared to zeolites was assigned to the lack of electrostatic confinement effect. This result may have a significant impact on the role of pore size on the reactivity and selectivity in hydrocracking reactions, which will be the object of future investigations.
We also investigated in more detail the interaction of $\mathrm{CO}$ as a probe molecule on all sites of the ASA model, ${ }^{104}$ as this molecule has been used for many years to characterize experimentally the acidity of various materials, ${ }^{122-125}$ including ASAs. ${ }^{56,96-99,120,126}$ Common sense suggests that the more positively charged the proton, the more acidic a surface $\mathrm{OH}_{-}$ group. $\mathrm{CO}$ is able to probe charges along the surface because of its dipolar nature. This perturbation induces a shift of the CO infrared stretching vibration usually measured by FTIR. The CO stretching vibrational frequency is indeed shifted $\left(\Delta \tilde{v}_{\mathrm{CO}}\right)$ and depends on the adsorption sites, which are both Brønsted and Lewis acid sites. It is generally admitted that the more acidic the adsorption site, the larger the shift of CO vibration. Nonetheless, we found that CO probes the surface electrostatic field, producing a vibrational Stark effect, which does not depend solely on the Brønsted acid character of the protons (this latter parameter being quantified by the proton transfer ability to lutidine, Fig. 7). On the ASA surface, the higher calculated shifts were assigned to some PBS-Al groups, likely due to the high electrostatic field imposed by

(a)

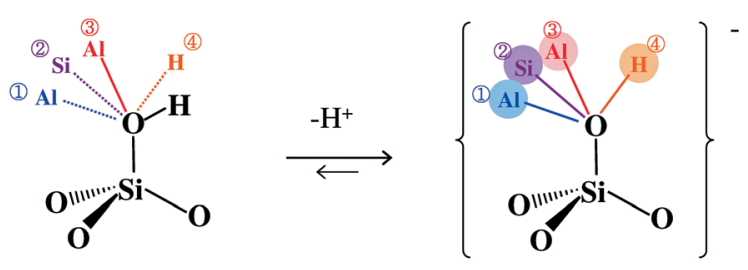

(b)

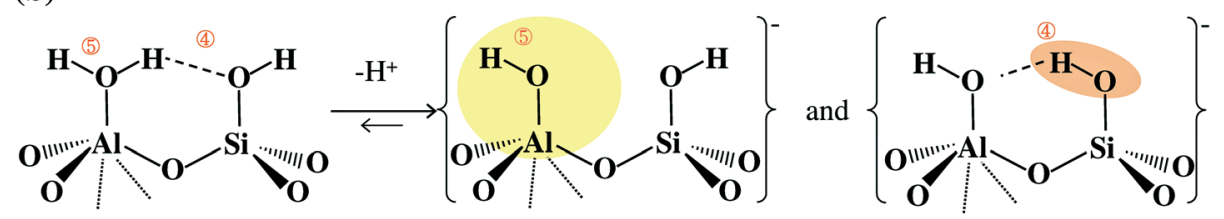

Fig. 6 Synopsis of the various Brønsted acid sites on the ASA surface: (a) PBS-Al (1)) and PBS-Si (2) are deprotonated by lutidine with the formation of new Al-O and $\mathrm{Si}-\mathrm{O}$ bonds. Bridging $\mathrm{OH}$ - groups (3) are deprotonated thanks to the existence of the Al-O bond. Silanol in the vicinity of labile protons (4), see also (b)) is deprotonated with cascade proton transfer from the water molecule. (b) Acidity induced by water molecules adsorbed on Al atoms: proton transfer by the water molecule itself (5) or cascade proton transfer to the neighboring silanol (4), see also (a)). Adapted with permission from ref. 103. Copyright 2011, Elsevier. 
(a)

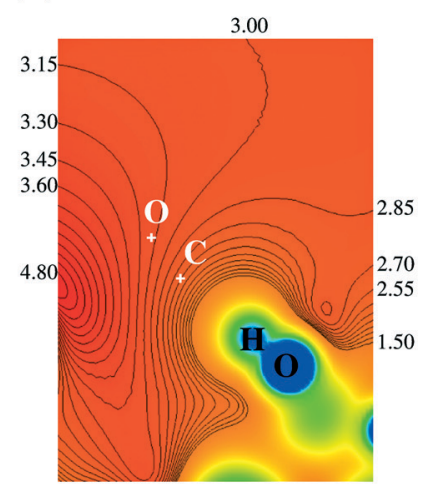

(b)

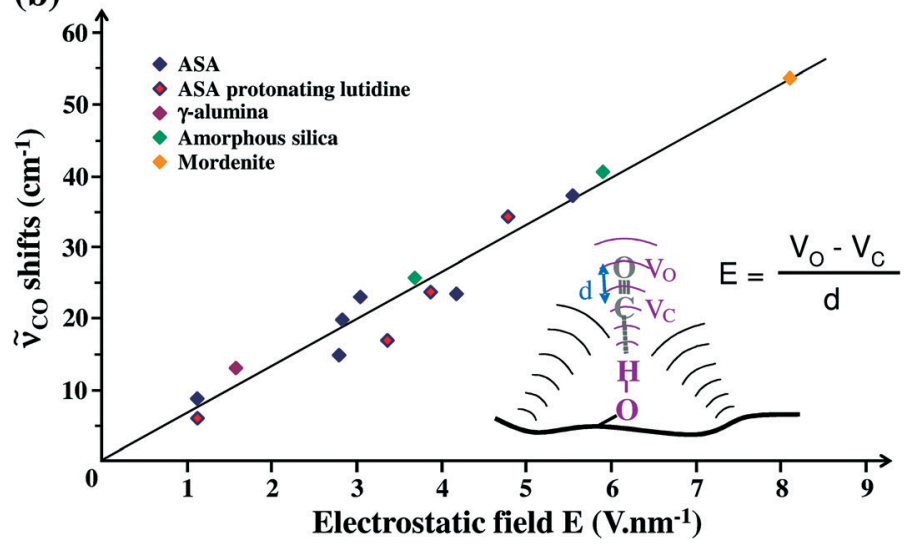

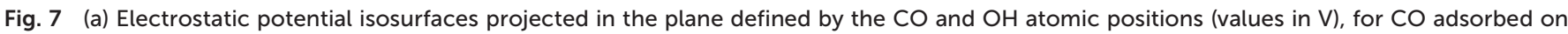

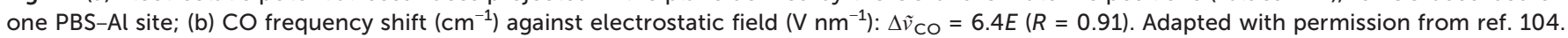
Copyright 2012, Royal Society of Chemistry.

aluminium cations. This shift $\left(\sim 35 \mathrm{~cm}^{-1}\right)$ is in good agreement with the signal experimentally assigned to "strong Brønsted acid sites". $56,98,120$

\section{Models of ultra-dispersed catalysts: noble metals supported on $\gamma-\mathrm{Al}_{2} \mathrm{O}_{3}$}

Platinum supported on $\gamma$-alumina $\left(\gamma-\mathrm{Al}_{2} \mathrm{O}_{3}\right)$ is a prominent catalyst involved in many different fields such as the treatment of automobile exhaust emissions, ${ }^{10}$ catalytic reforming, ${ }^{9}$ alkane dehydrogenation, ${ }^{127}$ and biomass conversion. ${ }^{80}$ In many catalytic processes, due to economic constraints, the optimal use of each Pt atom as an active site is critical and, thus, it is sought to reach subnanometer particle sizes while keeping their metallic properties. The $\gamma$ polymorph of alumina, possibly chlorinated, is the most widely used in industry due to its advantageous porosity, surface area and chemical properties. ${ }^{128}$ Catalytic reforming is one of the applications of interest where subnanometer-size particles are of great importance and where the effect of the support is also predominant. ${ }^{9}$ In this case, Pt is usually highly dispersed (content lower than $1 \mathrm{wt} \%$ ). The level of complexity of these catalysts is high, due to the subnanometer size of the particles, to the presence of dopants in the metallic phase (other metals such as Sn) and on the support (chlorine or indium, for example). The reaction network in which they are involved is also very complex, due to the bifunctional nature of the system (metallic and acidic phase) and the various desired (isomerization, dehydrogenation, dehydrocyclization) and undesired (coking, hydrogenolysis, cracking) reactions.

HRTEM $^{129-133}$ and STM $^{134,135}$ have provided precious insights for 2D supported metallic structures, while X-ray absorption spectroscopy (XAS) ${ }^{33,133,136-140}$ has been successfully applied to get 3D structural information. However, these techniques do not provide a single unambiguous particle model, so that many questions remain open about these highly fluxional structures under reactant pressure. To gain a deeper insight into the structure and behaviour of active sites in catalytic reforming, we performed DFT calculations coupled to a thermodynamic model. The complexity of the industrial multi-metallic catalyst was taken into account by a step-by-step approach, dealing first with monometallic, and then multimetallic systems.

Several first-principles studies of Pt/alumina systems based on $a b$ initio calculations have been reported in the literature by other research groups. They differ first in the nature of the alumina surface model. Very often, ideal $\alpha-\mathrm{Al}_{2} \mathrm{O}_{3}$ surfaces were considered. ${ }^{141-148}$ The abundance of $\mathrm{Al}_{\text {IV }}$ atoms in $\gamma-\mathrm{Al}_{2} \mathrm{O}_{3}$, which are absent in $\alpha-\mathrm{Al}_{2} \mathrm{O}_{3}$, however, makes the explicit study of the $\gamma$ polymorph needed. The hydroxylation state of the support has been addressed in some studies; ${ }^{147-149}$ however, its influence on the morphology of a polyatomic cluster has not been investigated. In general, the simulated sizes remained well below the real sizes of high dispersion oxide-supported metal clusters with diameters distributed around $1 \mathrm{~nm}$. Only recently, supported $\mathrm{Pt}_{10}{ }^{150}$ and $\mathrm{Pt}_{19}{ }^{151}$ particles have been simulated, but with limited investigation into the morphology of the clusters. Our work, presented below, is thus one of the first achievements of morphology definition of platinum clusters of reasonable size $\left(\mathrm{Pt}_{13}\right)$ supported on a realistic $\gamma-\mathrm{Al}_{2} \mathrm{O}_{3}$ surface model. We have also addressed for the first time supported PtSn systems ${ }^{152}$ which has been followed by complementary research of other groups. ${ }^{153}$

\subsection{Size and morphology effects in ultra-dispersed platinum catalysts}

Relevant models of monometallic platinum particles supported on dehydrated, hydroxylated and chlorinated $\gamma$-alumina were firstly elaborated, ${ }^{154,155}$ based on alumina support models presented in Section 1, and on models of metallic non-supported clusters. ${ }^{156}$ Platinum clusters containing 13 atoms were considered as being representative of highly dispersed platinum catalysts with particle size close to $1 \mathrm{~nm}$. Symmetric morphologies, such as cuboctahedron or 
icosahedron, appeared to be less favourable than less symmetric structures in the gas phase (Fig. 8-(a)), as biplanar structures, or irregular edifices obtained by simulated annealing sequences. ${ }^{156}$ Smaller particles (from 1 to 5 atoms) were also considered, since HRTEM suggests the occurrence of atomically dispersed Pt species. ${ }^{131,132}$ The alumina (100) surface is generally dehydroxylated in catalytic reforming conditions, whereas the (110) surface is still hydroxylated, ${ }^{74,77}$ possibly chlorinated. ${ }^{90}$ For isolated clusters, the following general rule holds: the bigger the size, the more stable the cluster (Fig. 8-(b)).

By contrast, DFT calculations performed on supported $\mathrm{Pt}_{1-13}$ clusters showed the significant impact of the rearrangement and migration of surface species (protons, hydroxyls, chlorine) for the stabilization of the smallest Pt clusters. ${ }^{155}$ This is mainly explained by the anchoring of the clusters to the surface via $\mathrm{Pt}-\mathrm{O}$ and $\mathrm{Pt}-\mathrm{Al}$ bonds. Taking into

(a)
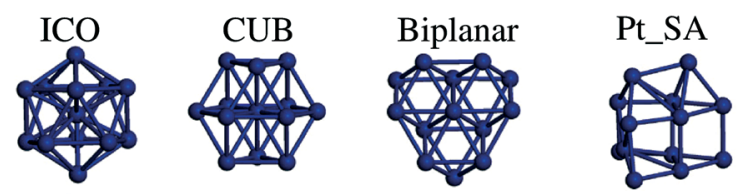

(b)

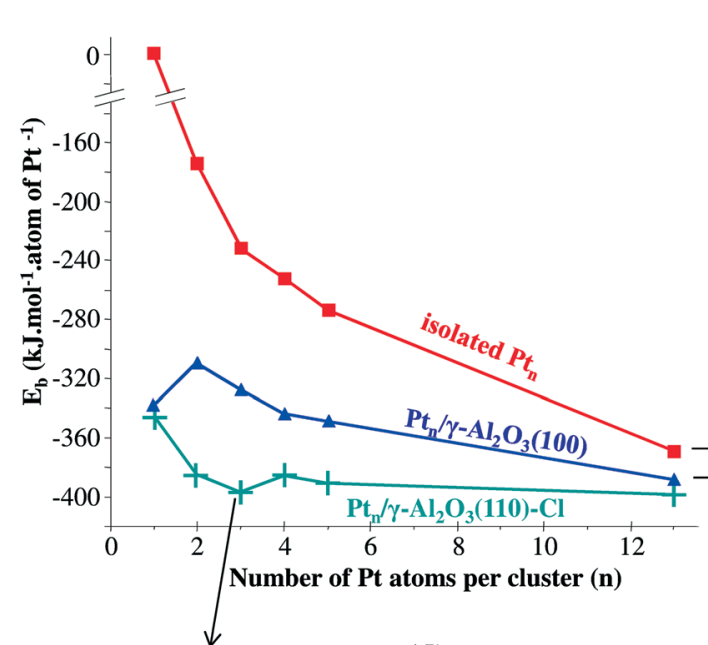

(c)

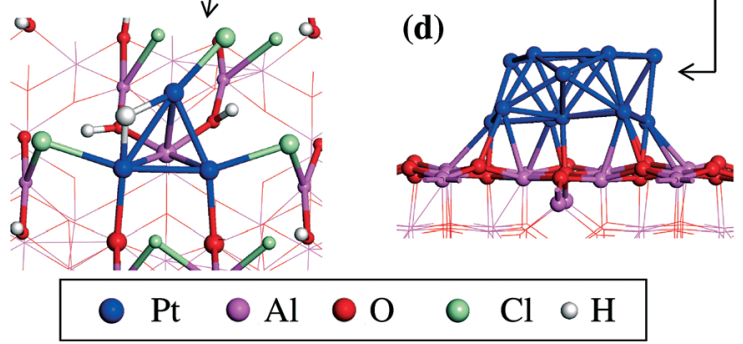

Fig. 8 (a) Some isolated $\mathrm{Pt}_{13}$ clusters studied in ref. 156: icosahedron, cuboctahedron, biplanar cluster and structure obtained by a simulated annealing sequence. Adapted with permission. Copyright 2009, American Physical Society. (b) Calculated binding energy (including $\mathrm{Pt}-\mathrm{Pt}$ cohesion and metal-support interaction) of $\mathrm{Pt}_{n}$ clusters, isolated or supported on $\gamma-\mathrm{Al}_{2} \mathrm{O}_{3}$. Adapted with permission from ref. 155. (c) Most stable $\mathrm{Pt}_{3}$ cluster supported on chlorinated $\gamma-\mathrm{Al}_{2} \mathrm{O}_{3}$ (110) surface. Adapted with permission from ref. 155. Copyright 2012, American Chemical Society. (d) Most stable $\mathrm{Pt}_{13}$ cluster supported on dehydrated (and dechlorinated) $\gamma-\mathrm{Al}_{2} \mathrm{O}_{3}$ (100) surface. Adapted with permission from ref. 154. Copyright 2010, Elsevier. account the migration of such surface species, Pt clusters are more stable on the hydrated and chlorinated (110) surfaces than on the dehydrated (100) surface. On the chlorinated (110) surfaces, $\mathrm{Pt}_{3}$ corresponds to a local energy minimum (Fig. 8-(b) and (c)), even lower than $\mathrm{Pt}_{13}$. This stability of $\mathrm{Pt}_{3}$ would explain an increase of the activation barrier to form larger clusters, thus limiting sintering, thanks to chlorine. ${ }^{137,157}$

\subsection{Hydrogen coverage effects on the structure of $\mathrm{Pt}_{13} / \gamma-\mathrm{Al}_{2} \mathrm{O}_{3}$}

In a second step, the reactivity of hydrogen towards platinum was investigated on the $\mathrm{Pt}_{13} / \gamma-\mathrm{Al}_{2} \mathrm{O}_{3}(100)$ system. ${ }^{88}$ Hydrogen is indeed present in the reactive medium, in particular in catalytic reforming, ${ }^{9}$ and titration methods aimed at quantifying the dispersion of the platinum particles often involve hydrogen adsorption. ${ }^{158}$

On the $\gamma-\mathrm{Al}_{2} \mathrm{O}_{3}(100)$ surface, in the absence of hydrogen, the $\mathrm{Pt}_{13}$ cluster preferentially lies in the "biplanar" (BP) morphology (Fig. 8-(d)) and maximizes the metal-support interaction through Pt-O and Pt-Al bonds. ${ }^{154}$ The calculations show that this structure presents a strong affinity towards hydrogen. Most stable structures for given hydrogen coverage (from 1 to 36 hydrogen atoms per cluster) were identified thanks to $a b$ initio molecular dynamics. A thermodynamic diagram was constructed, providing the surface state as a function of the temperature and hydrogen partial pressure (Fig. 9-(a)). The increase of hydrogen coverage may reach a $\mathrm{H} / \mathrm{Pt}$ atomic ratio greater than 1.4, which induces a cluster reconstruction from the BP to a cuboctahedral (CUB) morphology.

The H/Pt ratio exceeding 1 - often observed in experimental analysis conditions ${ }^{130,159}$ - is rationalized by this reconstruction process. Charge analysis reveals that a hydride phase is obtained for the $\mathrm{Pt}_{13}$ CUB structure, with the partial loss of the metallic nature. In contrast, for reaction conditions such as catalytic reforming $\left(T \sim 800 \mathrm{~K}\right.$ and $P\left(\mathrm{H}_{2}\right)$ $\sim 10$ bar), the particle remains biplanar with moderate $\mathrm{H} / \mathrm{Pt}$ ratio (0.5-1). The electronic analysis also shows that it keeps its metallic character. These results account for the numerous experimental data (TPD, XAS, HRTEM, etc.). ${ }^{160-165}$

The $\mathrm{H}$ coverage effects are also worth considering when choosing the ideal surface models. Fig. 9-(b) and -(c) depict the thermodynamic diagram calculated for the hydrogen/ $\mathrm{Pt}(111)$ and hydrogen/Pt(100) systems. For similar thermodynamic conditions, the $\mathrm{H}$ uptake of the supported $\mathrm{Pt}_{13}$ cluster is higher than that of extended $\mathrm{Pt}(111)$ and $\mathrm{Pt}(100)$ surfaces. For example, at $P\left(\mathrm{H}_{2}\right)=P^{\circ}=0.1 \mathrm{MPa}$, ideal surfaces exposed by large particles are depleted from $\mathrm{H}$ atoms at $T>900 \mathrm{~K}$, whereas the $\mathrm{Pt}_{13}$ cluster still contains six $\mathrm{H}$ atoms. This illustrates the non-relevance of ideal surface models for depicting the adsorption thermodynamics on subnanometric clusters, and also the importance of considering $\mathrm{H}$ coverage effects for the description of ideal surfaces in operating conditions, as $\theta_{\mathbf{H}}$ deviates from 0 ML (monolayer) for a large set of $\left(T, P\left(\mathrm{H}_{2}\right)\right)$ conditions. 
(a)

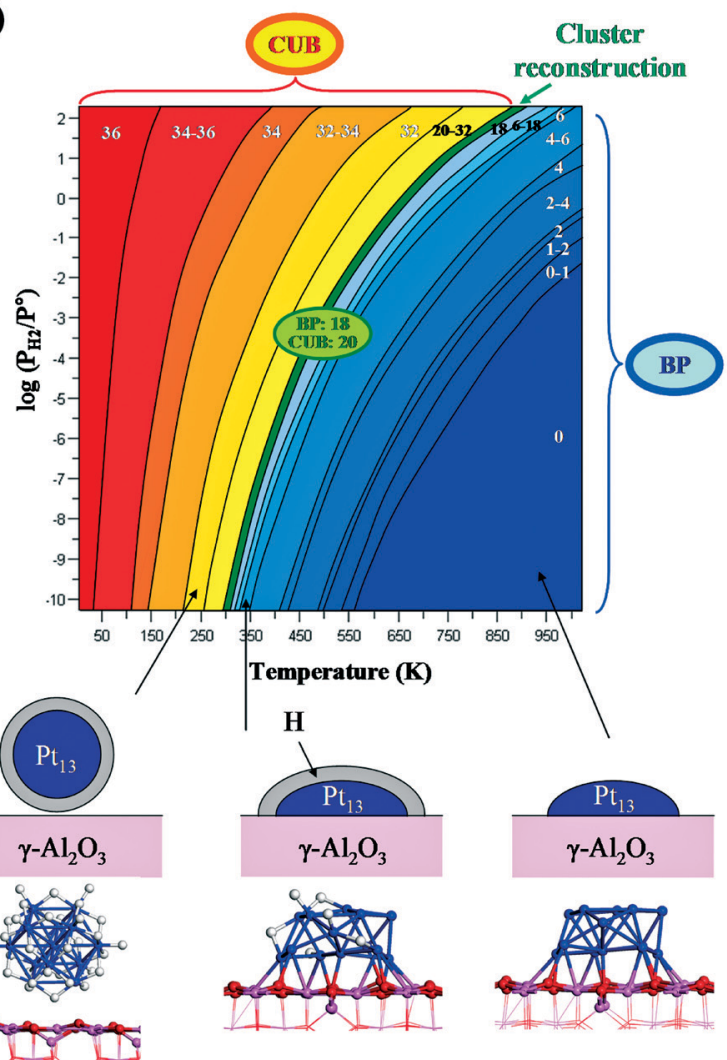

(b)

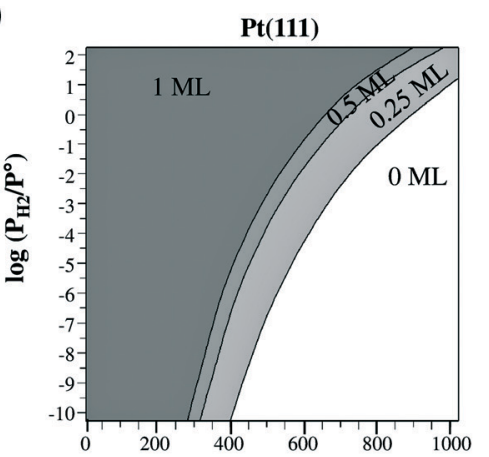

(c)

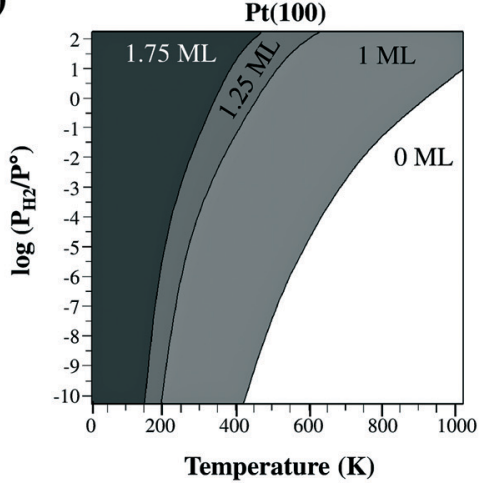

Fig. 9 Effect of hydrogen pressure on: (a) the morphology and $\mathrm{H}$ coverage changes of supported $\mathrm{Pt}_{13} / \gamma-\mathrm{Al}_{2} \mathrm{O}_{3}$, (b) $\mathrm{H}$ coverage on $\mathrm{Pt}(111)$, and (c) $\mathrm{H}$ coverage on $\mathrm{Pt}(100)$. Adapted with permission from ref. 88. Copyright 2011, Wiley and Sons.

\subsection{Hydrogen coverage effect on the stability of intermediates} of ethane dehydrogenation on $\mathrm{Pt}_{13} /(100) \gamma-\mathrm{Al}_{2} \mathrm{O}_{3}$

Then, to understand the impact of hydrogen in the catalytic reactions, in particular alkane dehydrogenation, we performed a DFT study of the stability of $\mathrm{C}_{x} \mathrm{H}_{y}(x=1$ or 2 and $0 \leq y \leq 5)$ intermediates, likely formed upon activation of ethane considered as a model molecule for probing $\mathrm{C}-\mathrm{C}$ and $\mathrm{C}-\mathrm{H}$ bond scission. ${ }^{20}$ Symmetric (one $\mathrm{H}$ removed on each $\mathrm{C}$ atom) and dissymmetric ( $\mathrm{H}$ removed first on the same $\mathrm{C}$ atom) dehydrogenation elementary steps were compared, as well as $\mathrm{C}-\mathrm{C}$ bond breaking with $\mathrm{CH}_{4}$ release. Calculated Gibbs free energy profiles at $800 \mathrm{~K}$ (representative of reforming conditions) for the transformation of ethane allowed the quantification of the relative stability of $\mathrm{C}_{x} \mathrm{H}_{y}$ species relevant for dehydrogenation and hydrogenolysis pathways as a function of reaction conditions. The impact of the $J=P\left(\mathrm{H}_{2}\right) / P$ (ethane) ratio $(J=0.01$, 1, 10 and 100) was studied (Fig. 10). According to the DFT and thermodynamic calculations, intermediate $J$ values between 1 and 10 correspond to the optimal balance between the two dehydrogenation pathways, the $\mathrm{C}-\mathrm{C}$ bond scission and formation of $\mathrm{CH}_{4}$. Simultaneously, ethylidyne $\left(\mathrm{CCH}_{3}\right.$ in Fig. 10), considered as a dead end intermediate, is thermodynamically less stable with respect to ethylene as soon as $J$ becomes greater than 1. Within a similar range of $J$, the hydrogenolysis reaction is also promoted due to the simultaneous stabilization of monocarbonaceous species on the platinum clusters with high hydrogen coverage. Regarding acetylene, its stability is more affected by the increase of $J$ (thus of $P\left(\mathrm{H}_{2}\right)$ ) than less dehydrogenated compounds. Moreover, the most stable cluster morphology when acetylene is adsorbed at $J=1$, for example, is no longer the biplanar one but the CUB one (Fig. 10).

As a consequence, we were able to identify and quantify the interval of process conditions to be used for moderate dehydrogenation of ethane into ethylene whilst avoiding further dehydrogenation, ethylidyne formation, hydrogenolysis and coke formation as targeted in process conditions. ${ }^{8,166,167}$

From a more general point of view, such hydrogen coverage effects also impact significantly the behaviour of an ideal surface, although it is often overlooked on these simple systems. For instance, in the selective hydrogenation of butadiene into butene, it has been shown that the competitive adsorption of hydrogen also significantly modifies the adsorption mode and thermochemistry of reactants and products on ideal Pd (111) and (100) surfaces. ${ }^{168}$

\subsection{Towards multi-metallic systems: $\mathrm{Pt}_{x} \mathrm{Sn}_{y} / \gamma-\mathrm{Al}_{2} \mathrm{O}_{3}(\mathrm{In})$}

The next step for a more accurate modelling of the real reforming catalyst is to consider the multi-metallic nature of the catalysts: bi-metallicity of the active phase and dopants in the alumina support. We recently undertook this theoretically 

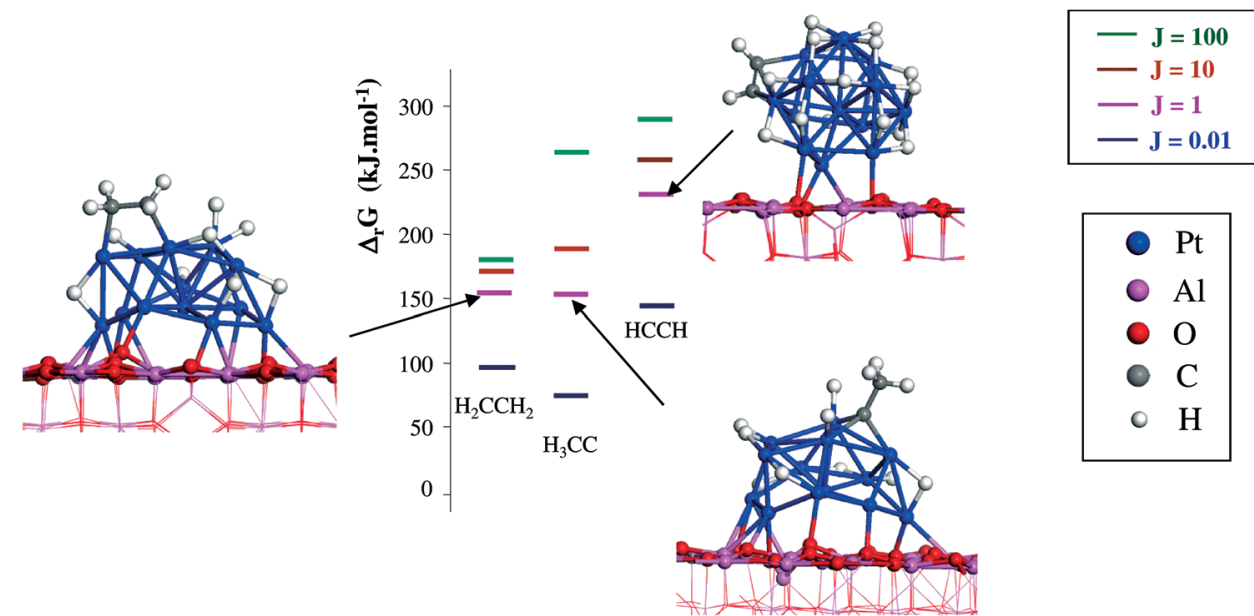

Fig. 10 Relative stabilities (Gibbs free energy of reaction of ethane) of adsorbed ethylene $\left(\mathrm{H}_{2} \mathrm{CCH}_{2}\right)$, ethylidyne $(\mathrm{CCH})$ and acetylene $(\mathrm{HCCH})$ on $\mathrm{Pt}_{13}$ supported cluster at various $J=P\left(\mathrm{H}_{2}\right) / P\left(\mathrm{C}_{2} \mathrm{H}_{6}\right)$ values. Insets: illustrations of structures at $J=1$. Adapted with permission from ref. 20 . Copyright 2013, Elsevier.

by focusing on PtSn formulations, possibly with indium as the co-doping element present in the support as $\operatorname{In}^{3+}$ (Fig. 11). ${ }^{152}$ While tin is shown to decrease the metal-support interaction as compared to pure platinum, indium compensates part of the interaction loss, which results in a stabilization of the bimetallic PtSn nano-cluster.

\section{Challenges for the realistic simulation of complex catalytic systems in catalytic conditions}

4.1 Current challenges in the simulation of complex aluminosilicate catalysts

The next step toward the understanding of the milder acidity of ASAs as compared with zeolites is the simulation of chemical reactivity, for the conversion of various molecules, involving the simulated Brønsted acid sites of ASA. As can be inferred from the adsorption of lutidine (see section 2), and from previous kinetic modelling of phenanthrene hydrocracking, ${ }^{169,170}$ the confinement effect (stronger within zeolites) will play a key role in proton-transfer reactions. We are currently investigating the cracking of alkenes as model
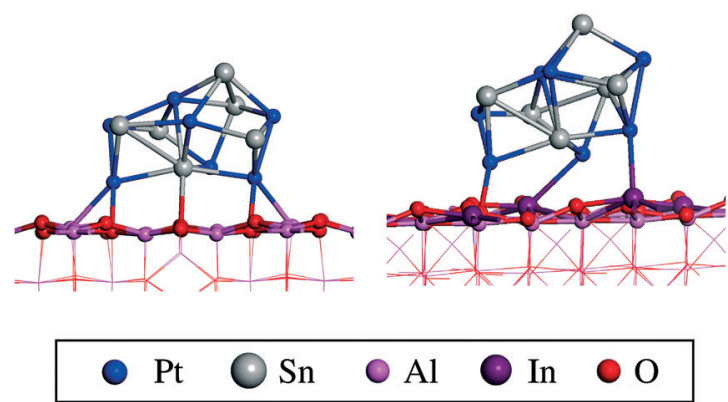

Fig. 11 Models of supported PtSn catalysts, without (left) or with (right) indium incorporated within the support. Adapted with permission from ref. 152. Copyright 2012, American Chemical Society. reactions for the genesis of carbenium species, and as topical for industrial applications (cracking, hydrocracking). The calculation of reaction rates, including enthalpy and entropy contributions, will be crucial both for the validation of the models (by comparison with experiments) and for the establishment of acidity scales within the family of aluminosilicates. More generally, the transferability of acid site structures, electrostatics and reactivity, to other complex aluminosilicate structures, needs to be understood, in particular thanks to first-principles calculations including van der Waals corrections (within the Grimme formalism for instance). To name a few, i.e. aluminated silica or ASAs obtained by the cogelification of aluminium and silicon precursors, ${ }^{109}$ amorphous microporous aluminosilicates obtained by aerosol techniques ${ }^{171}$ the internal surface of organized mesoporous silicas doped with $\mathrm{Al}^{109}$ the defects of dealuminateddesilicated zeolites, ${ }^{172}$ and external surfaces of zeolites (at the origin of the so-called "pore mouth" catalysis ${ }^{173,174}$ ), these are poorly defined systems at the atomic scale, which need detailed investigations. Likely, pseudo-bridging silanols could be found as relevant acid sites on all those amorphous systems, with variable $\mathrm{Si}-\mathrm{O}-\mathrm{Al}$ angles and/or variable $\mathrm{Al}$ coordination numbers. The local structure of the active site is the first parameter governing acidity. In addition, the confinement effect (van der Waals and electrostatic) induced by tunable mesopore sizes is the second parameter driving the acidity strength at the mesoscale. These combined effects still need further rational and quantified theoretical investigations in order to assist with the better control of targeted activity and selectivity in industrial reactions such as isomerization and (hydro)cracking.

\subsection{Current challenges in the simulation of ultra-dispersed catalysts}

DFT calculations appear as an appropriate tool to rationalize the behaviour of complex metallic systems at the molecular 
scale. Experiments are challenged by proposals coming from our studies. ${ }^{140,165}$ Experimental characterization is currently being performed to validate some key-features of our theoretical study, in our team and by other research groups. ${ }^{140}$ The impact of tin on the interaction with hydrogen is also being investigated. Other perspectives are oriented towards the reactivity of such particles with alkanes having a longer chain length.

More generally, the challenges in the field are the appropriate simulation of the multi-component nature of the system, taking into account non-reduced metal atoms, dopants and additives, and their impact on the chemical reactivity of the particles within complex reaction networks, involving various types of reactants (hydrocarbons, oxygenates, pollutants, etc.). Throughout such studies, the impact of the reconstruction of the particles should be taken into account.

It remains rather difficult to conclude if theoretical studies based on infinite metallic surface models and deriving socalled "universal" trends (as mentioned in the Introduction) can be applied to such multi-component catalysts. To the best of our current understanding, we suggest remaining cautious when using simplified structure-activity relationships in the case of highly dispersed catalysts because the risk of missing the chemical cornerstone of the catalyst is always present.

\subsection{General challenges}

The previous examples have highlighted that the modelling of complex catalytic systems at the atomic scale remains a current challenge, notwithstanding the significant improvement in the efficiency of computational tools over the past decades. Indeed, this research area would not be possible without the exponential increase of computing architecture performances and the significant developments of efficient quantum physics software algorithms. ${ }^{175}$ At the same time, a continuous improvement of the accuracy in the determination of the energy and geometry of a given system has been achieved by quantum calculation. ${ }^{43}$ However, undertaking a rational approach to propose a relevant - and not just arbitrary - model, remains a limiting step in this field.

Ideal surface approaches or derived descriptor approaches have the advantage of being simpler and quicker methods, opening the door of predictions based on periodic trends. ${ }^{50,176-180}$ They rationalize the first screening approach that could be sustained by high-throughput experimentation, during the search for a new catalytic formulation for a specific reaction. ${ }^{181}$ However, this can only be the first-order level of computational assistance for the development and improvement of catalysts, which then need a finer molecularscale description of the real catalytic systems beyond the first-order level. Thus the right level of complexity must be considered to allow further progresses in the field.

The main perspective of the works presented here is to gain an ever more relevant level of complexity in simulated systems, so as to provide an optimal model and accurate chemical descriptors that are valid for industrial catalysts. For example, doping elements or cations and anions issued from the precursors during synthesis on alumina-based supports is known to influence the catalytic properties. Regarding ultra-dispersed platinum-based catalysts, the detailed role of promoters and the impact of their oxidation state (in particular for $\mathrm{Sn}$ ) should be taken into account. It may also be of crucial interest for industrial catalysts to get a better quantitative understanding of the stability and reactivity of such multi-metallic nanoparticles on modified alumina surfaces (for example silica-alumina). This would help to provide a control at the molecular level of the balance between Brønsted acid sites and metallic sites, which is of fundamental and applied interest for bifunctional catalysts. $^{79}$

One future guideline for such a research is the simulation of all steps of the synthesis and activation procedure of the studied catalysts. In particular, challenging perspectives are the simulation of the solid-liquid interface between the support and the synthesis solutions with significant dynamic solvent effects, possibly charge separation, ${ }^{182-184}$ as well as calcination/reduction steps where the mobility of the active phases is high. In particular, the use of state-of-the-art (ab initio or force-field-based) molecular dynamic strategies will be key in this field. However, it must be stressed that developing the optimal techniques and approaches to better understand chemical phenomena taking place at solid-liquid interfaces remains a challenge, not only for theoreticians but also for experimentalists. ${ }^{185}$

In this spirit, once accurate models are established for a given catalyst, considering realistic reaction media and the interaction of the catalysts with each component of the gaseous or liquid phase is a complex task. ${ }^{186,187}$ We illustrated above how temperature and pressure effects can be taken into consideration in the simulation, but complex mixtures of large molecules are sometimes involved in real reactions. A quantum tool is probably not the most appropriate one to describe the reactivity of such systems: a reactive force-field can be one - although not trivial - solution. ${ }^{188}$

Finally, understanding and predicting the macroscopic catalytic performance also requires the limitations induced by the combined effects of kinetics, diffusion, convection, local evolution of the temperature and pressures/concentrations to be taken into account. Such a global process can only be modelled thanks to a multiscale approach, integrating quantum descriptors, kinetic modelling and reactor models. ${ }^{43,189-191}$ For this purpose, collecting systematic DFT data as a function of surface coverage imposed by reaction conditions is necessary. Significant achievements have been reported in this field, but usually starting from DFT models of ideal metal ${ }^{192-194}$ or oxide $^{189,195}$ surfaces. Integrating data for more and more realistic and coverage-dependent DFT models will provide improved description and prediction abilities for catalytic developments. 


\section{Conclusions}

The objective of the present paper was to illustrate the need for accurate models of heterogeneous catalysts, obtained by $a b$ initio calculations, which take into account, as far as possible, the complexity of the real catalytic system. To exemplify such an approach, we focused on two systems which have attracted much attention recently in our research work, by means of Density Functional Theory calculations: amorphous silica alumina surfaces and subnanometer-sized platinum particles, possibly doped, supported on $\gamma$-alumina. These two systems are challenging as they are of significant fundamental and industrial interest, and also due to their complexity, inherent multi-element composition, structural disorder, and small particle size. Climbing the ladder of complexity, a stepby-step investigation led us to propose rational models of such systems. Extended comparison with the most advanced experimental characterizations is the key for validation of these models. Atomic insights are then provided, which are not easily reached by experimental techniques only, even cutting-edge ones such as in situ XAS or operando IR. In particular, pseudo-bridging silanols have been proposed as key active sites on amorphous silica-alumina, whereas a hydrogen-induced reconstruction of platinum particles is anticipated thanks to DFT calculations. This latter example addresses probably one of the highest levels of complexity for a catalytic system: it combines a system with no symmetry, a nanoparticle deposited on a support, which is highly sensitive to reaction conditions, and support effects themselves. For such systems, quantum descriptors used in the so-called "universal" trends evaluated at ultra-low reactant coverage on ideal (infinite) surfaces must be considered with great care. Dedicated theoretical investigations compared with welldefined experiments are certainly mandatory to identify what can be defined as relevant, if not "universal", quantum descriptors. However, even if future experimental investigations may reveal some interesting catalytic systems which do not match with the so-called "universal" trends proposed nowadays, we hope that the present perspective has highlighted alternative routes for simulation approaches to tackle these "non-universal" cases by considering their own complexities.

\section{Acknowledgements}

We warmly thank Hervé Toulhoat (IFP Energies nouvelles) and Philippe Sautet (Ecole Normale Supérieure de Lyon) for long-lasting collaborations on some of these topics. Fruitful discussions with partners from theory and experiments are acknowledged, in particular with D. Costa (Chimie Paris Tech), M. Digne, A. Chaumonnot, M. Caillot, V. Moizan-Baslé, P. Avenier, S. Lacombe, A. Jahel (IFP Energies nouvelles), and J. van Bokhoven (ETH Zürich). We are indebted to former post-doc and PhD collaborators at IFP Energies nouvelles, namely F. Leydier, C.H. Hu, C. Mager-Maury and G. Bonnard for collaborative work reported in the present perspective.

\section{References}

1 R. Schlögl, Angew. Chem., Int. Ed., 2003, 42, 2004-2008.

2 J. W. Erisman, M. A. Sutton, J. Galloway, Z. Klimont and W. Winiwarter, Nat. Geosci., 2008, 1, 636-639.

3 P. Raybaud and H. Toulhoat, Catalysis by Transition Metal Sulphides, From Molecular Theory to Industrial Application, Technip, Paris, 2013.

4 J. L. Casci, C. M. Lok and M. D. Shannon, Catal. Today, 2009, 145, 38-44.

5 G. P. Van Der Laan and A. A. C. M. Beenackers, Catal. Rev. Sci. Eng., 1999, 41, 255-318.

6 H. Schulz, Appl. Catal., A, 1999, 186, 3-12.

7 C. Marcilly, Acido-basic Catalysis, Technip, Paris, 2005.

8 J. P. Franck, in Fundamental and industrial aspects of catalysis by metals, ed. B. Imelik, G. A. Martin and A. J. Renouprez, Editions du CNRS, Paris, 1984, p. 412.

9 J. H. Sinfelt, in Handbook of Heterogeneous Catalysis, ed. G. Ertl, E. Knözinger and J. Weitkamp, Wiley, Weinheim, 1997, pp. 1939-1955.

10 R. J. Farrauto and R. M. Heck, Catal. Today, 1999, 51, 351-360.

11 J. Kašpar, P. Fornasiero and N. Hickey, Catal. Today, 2003, 77, 419-449.

12 R. Burch, Catal. Rev. Sci. Eng., 2004, 46, 271-334.

13 S. Roy and A. Baiker, Chem. Rev., 2009, 109, 4054-4091.

14 P. Granger and V. I. Parvulescu, Chem. Rev., 2011, 111, 3155-3207.

15 P. Sabatier, La Catalyse en Chimie Organique, C. Beranger, Paris, 1913.

16 I. Langmuir, Chem. Rev., 1930, 6, 451-479.

17 G. Ertl, Angew. Chem., Int. Ed., 2008, 47, 3524-3535.

18 A. C. Byrns, W. E. Bradley and M. W. Lee, Ind. Eng. Chem., 1943, 35, 1160-1167.

19 O. Weisser and S. Landa, Sulphide catalysts: their properties and applications, Pergamon Press, 1973.

20 P. Raybaud, C. Chizallet, C. Mager-Maury, M. Digne, H. Toulhoat and P. Sautet, J. Catal., 2013, 308, 328-340.

21 F. Schüth, O. Busch, C. Hoffmann, T. Johann, C. Kiener, D. Demuth, J. Klein, S. Schunk, W. Strehlau and T. Zech, Top. Catal., 2002, 21, 55-66.

22 K. Jähnisch, V. Hessel, H. Löwe and M. Baerns, Angew. Chem., Int. Ed., 2004, 43, 406-446.

23 C. Mirodatos, Oil Gas Sci. Technol., 2013, 68, 403-413.

24 G. Ertl and H.-J. Freund, Phys. Today, 1999, 52, 32-38.

25 C. R. Henry, Surf. Sci. Rep., 1998, 31, 231-325.

26 F. Zaera, Prog. Surf. Sci., 2001, 69, 1-98.

27 H.-J. Freund, Surf. Sci., 2002, 500, 271-299.

28 H. J. Freund, Chem. - Eur. J., 2010, 16, 9384-9397.

29 G. A. Somorjai, H. Frei and J. Y. Park, J. Am. Chem. Soc., 2009, 131, 16589-16605.

30 F. Meunier, ACS Nano, 2008, 2, 2441-2444.

31 H. Friedrich, P. E. de Jongh, A. J. Verkleij and K. P. de Jong, Chem. Rev., 2009, 109, 1613-1629.

32 B. M. Weckhuysen, Angew. Chem., Int. Ed., 2009, 48, 4910-4943. 
33 S. Bordiga, E. Groppo, G. Agostini, J. A. van Bokhoven and C. Lamberti, Chem. Rev., 2013, 113, 1736-1850.

34 I. L. Buurmans and B. M. Weckhuysen, Nat. Chem., 2012, 4, 873-886.

35 A. Brückner, Catal. Rev. Sci. Eng., 2003, 45, 97-150.

36 M. A. Bañares, Catal. Today, 2005, 100, 71-77.

37 J. T. Gleaves, G. S. Yablonskii, P. Phanawadee and Y. Schuurman, Appl. Catal., A, 1997, 160, 55-88.

38 J. Schweicher, A. Bundhoo, A. Frennet, N. Kruse, H. Daly and F. C. Meunier, J. Phys. Chem. C, 2010, 114, 2248-2255.

39 A. T. Bell, Science, 2003, 299, 1688-1691.

40 P. Hohenberg and W. Kohn, Phys. Rev., 1964, 136, B864-B871.

41 R. A. van Santen and M. Neurock, Molecular Heterogeneous Catalysis, Wiley-VCH, Weinheim, 2006.

42 R. A. van Santen and P. Sautet, Computational Methods in Catalysis and Materials Science, Wiley-VCH, Weinheim, 2009.

43 M. K. Sabbe, M.-F. Reyniers and K. Reuter, Catal. Sci. Technol., 2012, 2, 2010-2024.

44 N. Lopez, N. Almora-Barrios, G. Carchini, P. Blonski, L. Bellarosa, R. Garcia-Muelas, G. Novell-Leruth and M. Garcia-Mota, Catal. Sci. Technol., 2012, 2, 2405-2417.

45 A. Warshel and M. Levitt, J. Mol. Biol., 1976, 103, 227-249.

46 J. Sauer and M. Sierka, J. Comput. Chem., 2000, 21, 1470-1493.

47 P. V. Sushko, J. L. Gavartin and A. L. Shluger, J. Phys. Chem. $B, 2002,106,2269-2276$.

48 J. Hafner, L. Benco and T. Bucko, Top. Catal., 2006, 37, 41-54.

49 B. Hammer and J. K. Nørskov, Adv. Catal., 2000, 45, 71-129.

50 J. K. Nørskov, T. Bligaard, J. Rossmeisl and C. H. Christensen, Nat. Chem., 2009, 1, 37-46.

51 R. van Santen, Acc. Chem. Res., 2009, 42, 57-66.

52 M. Che and A. J. Tench, Adv. Catal., 1982, 31, 77-133.

53 M. L. Bailly, C. Chizallet, G. Costentin, J. M. Krafft, H. Lauron-Pernot and M. Che, J. Catal., 2005, 235, 413-422.

54 C. Chizallet, S. Lazare, D. Bazer-Bachi, F. Bonnier, V. Lecocq, E. Soyer, A. A. Quoineaud and N. Bats, J. Am. Chem. Soc., 2010, 132, 12365-12377.

55 M. Behrens, F. Studt, I. Kasatkin, S. Kühl, M. Häveker, F. Abild-Pedersen, S. Zander, F. Girgsdies, P. Kurr, B. J. Kniep, M. Tovar, R. W. Fischer, J. K. Nørskov and R. Schlögl, Science, 2012, 336, 893-897.

56 O. Cairon, T. Chevreau and J. C. Lavalley, J. Chem. Soc., Faraday Trans., 1998, 94, 3039-3047.

57 J. To, A. A. Sokol, S. A. French, C. R. A. Catlow, P. Sherwood and H. J. J. van Dam, Angew. Chem., Int. Ed., 2006, 45, 1633-1638.

58 S. Polarz, J. Strunk, V. Ischenko, M. W. E. van den Berg, O. Hinrichsen, M. Muhler and M. Driess, Angew. Chem., Int. Ed., 2006, 45, 2965-2969.

59 S. A. French, A. A. Sokol, S. T. Bromley, C. R. A. Catlow, S. C. Rogers, F. King and P. Sherwood, Angew. Chem., Int. Ed., 2001, 40, 4437.

60 C. Wöll, Prog. Surf. Sci., 2007, 82, 55-120.
61 F. Esch, S. Fabris, L. Zhou, T. Montini, C. Africh, P. Fornasiero, G. Comelli and R. Rosei, Science, 2005, 309, 752-755.

62 C. Drouilly, J. M. Krafft, F. Averseng, H. Lauron-Pernot, D. Bazer-Bachi, C. Chizallet, V. Lecocq and G. Costentin, Appl. Catal., A, 2013, 453, 121-129.

63 M. Breysse, P. Afanasiev, C. Geantet and M. Vrinat, Catal. Today, 2003, 86, 5-16.

64 B. M. Weckhuysen and D. E. Keller, Catal. Today, 2003, 78, 25-46.

65 M. Comotti, W.-C. Li, B. Spliethoff and F. Schüth, J. Am. Chem. Soc., 2006, 128, 917-924.

66 C. Bouchy, G. Hastoy, E. Guillon and J. A. Martens, Oil Gas Sci. Technol., 2009, 64, 91-112.

67 K. Reuter and M. Scheffler, Phys. Rev. Lett., 2003, 90, 046103.

68 J. Rogal, K. Reuter and M. Scheffler, Phys. Rev. Lett., 2007, 98, 04610.

69 D. Teschner, J. Borsodi, A. Wootsch, Z. Révay, M. Hävecker, A. Knop-Gericke, S. D. KJackson and R. Schlögl, Science, 2008, 320, 86-89.

70 D. Teschner, Z. Révay, J. Borsodi, M. Hävecker, A. Knop-Gericke, R. Schlögl, D. Milroy, S. D. Jackson, D. Torres and P. Sautet, Angew. Chem., Int. Ed., 2008, 47, 9274-9278.

71 M. Armbrüster, M. Behrens, F. Cinquini, K. Föttinger, Y. Grin, A. Haghofer, B. Klötzer, A. Knop-Gericke, H. Lorenz, A. Ota, S. Penner, J. Prinz, C. Rameshan, Z. Révay, D. Rosenthal, G. Rupprechter, P. Sautet, R. Schlögl, L. Shao, L. Szentmiklósi, D. Teschner, D. Torres, R. Wagner, R. Widmer and G. Wowsnick, ChemCatChem, 2012, 4, 1048-1063.

72 I. M. Ciobîcă, R. A. van Santen, P. J. van Berge and J. van de Loosdrecht, Surf. Sci., 2008, 602, 17-27.

73 M. Digne, P. Sautet, P. Raybaud, P. Euzen and H. Toulhoat, J. Catal., 2002, 211, 1-5.

74 M. Digne, P. Sautet, P. Raybaud, P. Euzen and H. Toulhoat, J. Catal., 2004, 226, 54-68.

75 C. Chizallet, G. Costentin, M. Che, F. Delbecq and P. Sautet, J. Phys. Chem. B, 2006, 110, 15878-15886.

76 S. T. Korhonen, M. Calatayud and A. O. Krause, J. Phys. Chem. C, 2008, 112, 6469-6476.

77 C. Arrouvel, M. Digne, M. Breysse, H. Toulhoat and P. Raybaud, J. Catal., 2004, 222, 152-166.

78 C. Chizallet, M. Digne, C. Arrouvel, P. Raybaud, F. Delbecq, G. Costentin, M. Che, P. Sautet and H. Toulhoat, Top. Catal., 2009, 52, 1005-1016.

79 J. Weitkamp, ChemCatChem, 2012, 4, 292-306.

80 G. W. Huber, R. D. Cortright and J. A. Dumesic, Angew. Chem., Int. Ed., 2004, 43, 1549-1551.

81 J. Q. Bond, D. M. Alonso, D. Wang, R. W. West and J. A. Dumesic, Science, 2010, 327, 1110-1114.

82 G. Kresse and J. Hafner, Phys. Rev. B: Condens. Matter, 1994, 49, 14251-14269.

83 G. Kresse and J. Furthmüller, Phys. Rev. B: Condens. Matter, 1996, 54, 11169.

84 J. Perdew and Y. Wang, Phys. Rev. B: Condens. Matter, 1992, 45, 13244-13249. 
85 J. Perdew, K. Burke and M. Ernzerhof, Phys. Rev. Lett., 1996, 77, 3865-3868.

86 G. Kresse and D. Joubert, Phys. Rev. B: Condens. Matter Mater. Phys., 1999, 59, 1758-1775.

87 C. Chizallet and P. Raybaud, Angew. Chem., Int. Ed., 2009, 48, 2891-2893.

88 C. Mager-Maury, G. Bonnard, C. Chizallet, P. Sautet and P. Raybaud, ChemCatChem, 2011, 3, 200-207.

89 X. Krokidis, P. Raybaud, A. E. Gobichon, B. Rebours, P. Euzen and H. Toulhoat, J. Phys. Chem. B, 2001, 105, 5121-5130.

90 M. Digne, P. Raybaud, P. Sautet, D. Guillaume and H. Toulhoat, J. Am. Chem. Soc., 2008, 130, 11030-11039.

91 J. Sauer, Chem. Rev., 1989, 89, 199-255.

92 R. van Santen and G. J. Kramer, Chem. Rev., 1995, 95, 637-660.

93 W. E. Farneth and R. J. Gorte, Chem. Rev., 1995, 95, 615-635.

94 G. Busca, Chem. Rev., 2007, 107, 5366-5410.

95 F. Bertoncini, A. Bonduelle-Skrzypcak, J. Francis and E. Guillon, in Catalysis by transition metal sulphides: from molecular theory to industrial applications, ed. H. Toulhoat and P. Raybaud, Technip, 2013, pp. 609-677.

96 M. Trombetta, G. Busca, S. Rossini, V. Piccoli, U. Cornaro, A. Guercio, R. Catani and R. J. Willey, J. Catal., 1998, 179, 581-596.

97 W. Daniell, U. Schubert, R. Glöckler, A. Meyer, K. Noweck and H. Knözinger, Appl. Catal., A, 2000, 196, 247-260.

98 G. Crépeau, V. Montouillout, A. Vimont, L. Mariey, T. Cseri and F. Maugé, J. Phys. Chem. B, 2006, 110, 15172-15185.

99 D. G. Poduval, J. A. R. van Veen, M. S. Rigutto and E. J. M. Hensen, Chem. Commun., 2010, 46, 3466-3468.

100 M. F. Williams, B. Fonfé, C. Sievers, A. Abraham, J. A. van Bokhoven, A. Jentys, J. A. R. van Veen and J. A. Lercher, J. Catal., 2007, 251, 485-496.

101 K. Gora-Marek, M. Derewinski, P. Sarv and J. Datka, Catal. Today, 2005, 101, 131-138.

102 C. Chizallet and P. Raybaud, ChemPhysChem, 2010, 11, 105-108.

103 F. Leydier, C. Chizallet, A. Chaumonnot, M. Digne, E. Soyer, A. A. Quoineaud, D. Costa and P. Raybaud, J. Catal., 2011, 284, 215-229.

104 F. Leydier, C. Chizallet, D. Costa and P. Raybaud, Chem. Commun., 2012, 48, 4076-4078.

105 A. Winkler, J. Horbach, W. Kob and K. Binder, J. Chem. Phys., 2004, 120, 384-393.

106 M. Benoit, S. Ispas and M. Tuckerman, Phys. Rev. B: Condens. Matter, 2001, 64, 224205.

107 R. Duchateau, R. J. Harmsen, H. C. L. Abbenhuis, R. van Santen, A. Meetsma, S. K. H. Thiele and M. Kranenburg, Chem. - Eur. J., 1999, 5, 3130-3135.

108 A. W. Moses, N. A. Ramsahye, C. Raab, H. D. Leifeste, S. Chattopadhyay, B. F. Chmelka, J. Eckert and S. L. Scott, Organometallics, 2006, 25, 2157-2165.

109 A. Chaumonnot, in Catalysis by transition metal sulphides: from molecular theory to industrial applications, ed. H. Toulhoat and P. Raybaud, Technip, 2013, pp. 225-243.
110 N. Katada and M. Niwa, Chem. Vap. Deposition, 1996, 2, 125-134.

111 J. D. Alexander, A. N. Gent and P. N. Henriksen, J. Chem. Phys., 1985, 83, 5981-5987.

112 M. Lindblad and A. Root, Stud. Surf. Sci. Catal., 1998, 118, 817-826.

113 P. Sarrazin, S. Kasztelan, N. Zanier-Szydlowski, J. P. Bonnelle and J. Grimblot, J. Phys. Chem., 1993, 97, 5947-5953.

114 B. M. De Witte, P. J. Grobet and J. B. Uytterhoeven, J. Phys. Chem., 1995, 99, 6961-6965.

115 J. P. Gilson, G. C. Edwards, A. W. Peters, K. Rajagopalan, R. F. Wormsbecher, T. G. Roberie and M. P. Shatlock, J. Chem. Soc., Chem. Commun., 1987, 91-92.

116 M. Caillot, A. Chaumonnot, M. Digne and J. A. V. Bokhoven, ChemCatChem, 2013, 5, 3644-3656.

117 F. Tielens, C. Gervais, J. F. Lambert, F. Mauri and D. Costa, Chem. Mater., 2008, 20, 3336-3344.

118 K. Gora-Marek and J. Datka, Appl. Catal., A, 2006, 302, 104-109.

119 B. Xu, C. Sievers, J. A. Lercher, J. A. R. van Veen, P. Giltay, R. Prins and J. A. van Bokhoven, J. Phys. Chem. C, 2007, 111, 12075-12079.

120 E. J. M. Hensen, D. G. Poduval, V. Degirmenci, D. A. J. M. Ligthart, W. Chen, F. Maugé, M. S. Rigutto and J. A. R. van Veen, J. Phys. Chem. C, 2012, 116, 21416-21429.

121 E. Garrone, B. Onida, B. Bonelli, C. Busco and P. Ugliengo, J. Phys. Chem. B, 2006, 110, 19087-19092.

122 H. Knözinger, in Handbook of Heterogeneous Catalysis, ed. G. Ertl, H. Knözinger and J. Weitkamp, Wiley, Weinheim, 1997, vol. 2, pp. 707-732.

123 A. Corma, Chem. Rev., 1995, 95, 559-614.

124 J. A. Lercher, C. Gründling and G. Eder-Mirth, Catal. Today, 1996, 27, 353-376.

125 A. Zecchina, C. Lamberti and S. Bordiga, Catal. Today, 1998, 41, 169-177.

126 O. Cairon, Phys. Chem. Chem. Phys., 2010, 12, 6333-6336.

127 S. Vajda, M. J. Pellin, J. P. Greeley, C. L. Marshall, L. A. Curtiss, G. E. Ballentine, J. M. Elam, S. Catillon-Mucherie, P. C. Redfern, F. Mehmood and P. Zapol, Nat. Mater., 2009, 8, 213-216.

128 P. Euzen, P. Raybaud, X. Krokidis, H. Toulhoat, J. L. Loarer, J.-P. Jolivet and C. Froidefond, in Handbook of Porous Solids, ed. F. Schüth, K. S. W. Sing and J. Weitkamp, Wiley-VCH, Weinheim, 2002.

129 P. D. Nellist and S. J. Pennycook, Science, 1996, 274, 413-415.

130 Y. Ji, A. M. J. van der Eerden, V. Koot, P. J. Kooyman, J. D. Meeldijk, B. M. Weckhuysen and D. C. Koningsberger, J. Catal., 2005, 234, 376-384.

131 J. H. Kwak, J. Hu, D. Mei, C. W. Yi, D. H. Kim, C. H. F. Peden, L. F. Allard and J. Szanyi, Science, 2009, 325, 1670-1673.

132 S. Bradley, W. Sinkler, D. Blom, W. Bigelow, P. Voyles and L. Allard, Catal. Lett., 2012, 142, 176-182. 
133 M. W. Small, S. I. Sanchez, N. S. Marinkovic, A. I. Frenkel and R. G. Nuzzo, ACS Nano, 2012, 6, 5583-5595.

134 A. K. Santra and D. W. Goodman, J. Phys.: Condens. Matter, 2002, 14, R31-R62.

135 M. Sterrer, T. Risse, L. Giordano, M. Heyde, N. Nuilius, H. P. Rust, G. Pacchioni and H.-J. Freund, Angew. Chem., Int. Ed., 2007, 46, 8703-8706.

136 J. H. Sinfelt, G. H. Via and F. W. Lytle, J. Chem. Phys., 1978, 68, 2009-2010.

137 J. Lynch, Oil Gas Sci. Technol., 2002, 57, 281-305.

138 M. K. Oudenhuijzen, J. A. van Bokhoven, J. T. Miller, D. E. Ramaker and D. C. Koningsberger, J. Am. Chem. Soc., 2005, 127, 1530-1540.

139 F. Behafarid, L. K. Ono, S. Mostafa, J. R. Croy, G. Shafai, S. Hong, T. S. Rahman, S. R. Bare and B. Roldan Cuenya, Phys. Chem. Chem. Phys., 2012, 14, 11766-11779.

140 H. Mistry, F. Behafarid, S. R. Bare and B. Roldan Cuenya, ChemCatChem, 2014, 6, 348-352.

141 C. Verdozzi, D. R. Jennison, P. A. Schultz and M. P. Sears, Phys. Rev. Lett., 1999, 82, 799-802.

142 V. A. Nasluzov, V. V. Rivanenkov, A. M. Shor, K. M. Neyman and N. Rösch, Chem. Phys. Lett., 2003, 374, 487-495.

143 V. V. Rivanenkov, V. A. Nasluzov, A. M. Shor, K. M. Neyman and N. Rösch, Surf. Sci., 2003, 525, 173-183.

144 B. Hinnemann and E. A. Carter, J. Phys. Chem. C, 2007, 111, 7105-7126.

145 C. Zhou, J. Wu, T. J. D. Kumar, N. Balakrishnan, R. C. Forrey and H. Cheng, J. Phys. Chem. C, 2007, 111, 13786-13793.

146 L. G. V. Briquet, C. R. A. Catlow and S. A. French, J. Phys. Chem. C, 2008, 112, 18948-18954.

147 L. G. V. Briquet, C. R. A. Catlow and S. A. French, J. Phys. Chem. C, 2009, 113, 16747-16756.

148 L. Xiao and W. F. Schneider, Surf. Sci., 2008, 602, 3445.

149 N. A. Deskins, D. Mei and M. Dupuis, Surf. Sci., 2009, 603, 2793-2807.

150 F. Vila, J. J. Rehr, J. Kas, R. G. Nuzzo and A. I. Frenkel, Phys. Rev. B: Condens. Matter Mater. Phys., 2008, 78, 121404.

151 F. Ahmed, M. K. Alam, A. Suzuki, M. Koyama, H. Tsuboi, N. Hatakeyama, A. Endou, H. Takaba, C. A. Del Carpio, M. Kubo and A. Miyamoto, J. Phys. Chem. C, 2009, 113, 15676-15683.

152 A. Jahel, V. Moizan-Baslé, C. Chizallet, P. Raybaud, J. Olivier-Fourcade, J. C. Jumas, P. Avenier and S. Lacombe, J. Phys. Chem. C, 2012, 116, 10073-10083.

153 F. D. Vila, J. J. Rehr, S. D. Kelly and S. R. Bare, J. Phys. Chem. C, 2013, 117, 12446-12457.

154 C. H. Hu, C. Chizallet, C. Mager-Maury, M. Corral Valero, P. Sautet, H. Toulhoat and P. Raybaud, J. Catal., 2010, 274, 99-110.

155 C. Mager-Maury, C. Chizallet, P. Sautet and P. Raybaud, ACS Catal., 2012, 2, 1346-1357.

156 C. H. Hu, C. Chizallet, H. Toulhoat and P. Raybaud, Phys. Rev. B: Condens. Matter, 2009, 79, 195416.
157 J. Berdala, E. Freund and J. Lynch, J. Phys., 1986, 47, 269-272.

158 D. J. O'Rear, D. G. Löffler and M. Boudart, J. Catal., 1990, 121, 131-140.

159 B. J. Kip, F. B. M. Duivenvoorden, D. C. Koningsberger and R. Prins, J. Catal., 1987, 105, 26-38.

160 P. Ferreira-Aparicio, A. Guerrero-Ruiz and I. Rodriguez-Ramos, J. Chem. Soc., Faraday Trans., 1997, 93, 3563-3567.

161 J. T. Miller, B. L. Meyers, F. S. Modica, G. S. Lane, M. Vaarkamp and D. C. Koningsberger, J. Catal., 1993, 143, 395-408.

162 E. Bus, J. T. Miller, A. J. Kropf, R. Prins and J. A. van Bokhoven, Phys. Chem. Chem. Phys., 2006, 8, 3248-3258.

163 S. I. Sanchez, L. D. Menard, A. Bram, J. H. Kang, M. W. Small, R. G. Nuzzo and A. I. Frenkel, J. Am. Chem. Soc., 2009, 131, 7040-7054.

164 J. Singh, R. C. Nelson, B. C. Vicente, S. L. Scott and J. A. van Bokhoven, Phys. Chem. Chem. Phys., 2010, 12, 5668-5677.

165 P. Raybaud, C. Chizallet, H. Toulhoat and P. Sautet, Phys. Chem. Chem. Phys., 2012, 14, 16773-16774.

166 G. C. Bond and R. H. Cunningham, J. Catal., 1997, 166, 172-185.

167 G. C. Bond, Catal. Today, 1999, 49, 41-48.

168 C. Chizallet, G. Bonnard, E. Krebs, L. Bisson, C. Thomazeau and P. Raybaud, J. Phys. Chem. C, 2011, 115, 12135-12149.

169 E. Benazzi, L. Leite, N. Marchal-George, H. Toulhoat and P. Raybaud, J. Catal., 2003, 217, 376-387.

170 H. Toulhoat, P. Raybaud and E. Benazzi, J. Catal., 2004, 221, 500-509.

171 S. Pega, C. Boissière, D. Grosso, T. Azaïs, A. Chaumonnot and C. Sanchez, Angew. Chem., Int. Ed., 2009, 48, 2784-2787.

172 M.-C. Silaghi, C. Chizallet and P. Raybaud, Microporous Mesoporous Mater., 2014, 191, 82-96.

173 J. A. Martens, G. Vanbutsele, P. A. Jacobs, J. Denayer, R. Ocakoglu, G. Baron, J. A. Muñoz Arroyo, J. Thybaut and G. B. Marin, Catal. Today, 2001, 65, 111-116.

174 J. A. Martens, W. Souverijns, W. Verrelst, R. Parton, G. F. Froment and P. A. Jacobs, Angew. Chem., Int. Ed. Engl., 1995, 34, 2528-2530.

175 W. A. de Jong, E. Bylaska, N. Govind, C. L. Janssen, K. Kowalski, T. Muller, I. M. B. Nielsen, H. J. J. van Dam, V. Veryazov and R. Lindh, Phys. Chem. Chem. Phys., 2010, 12, 6896-6920.

176 J. K. Nørskov, T. Bligaard, A. Logadottir, S. Bahn, L. B. Hansen, M. Bollinger, H. Bengaard, B. Hammer, Z. Sljivancanin, M. Mavrikakis, Y. Xu, S. Dahl and C. J. H. Jacobsen, J. Catal., 2002, 209, 275-278.

177 H. Toulhoat and P. Raybaud, J. Catal., 2003, 216, 63-72.

178 R. van Santen, M. Neurock and S. G. Shetty, Chem. Rev., 2010, 110, 2005-2048.

179 J. K. Nørskov and T. Bligaard, Angew. Chem., Int. Ed., 2013, 52, 776-777.

180 F. Corvaisier, Y. Schuurman, A. Fecant, C. Thomazeau, P. Raybaud, H. Toulhoat and D. Farrusseng, J. Catal., 2013, 307, 352-361. 
181 E. J. Ras, M. J. Louwerse, M. C. Mittelmeijer-Hazeleger and G. Rothenberg, Phys. Chem. Chem. Phys., 2013, 15, 4436-4443.

182 E. Johnson, Science, 2002, 296, 477-478.

183 M.-P. Gaigeot, M. Sprik and M. Sulpizi, J. Phys.: Condens. Matter, 2012, 24, 124106.

184 J. Carrasco, A. Hodgson and A. Michaelides, Nat. Mater., 2012, 11, 667-674.

185 F. Zaera, Chem. Rev., 2012, 112, 2920-2986.

186 S. Laref, Y. Li, M.-L. Bocquet, F. Delbecq, P. Sautet and D. Loffreda, Phys. Chem. Chem. Phys., 2011, 13, 11827-11837.

187 B. N. Zope, D. D. Hibbits, M. Neurock and R. J. Davis, Science, 2010, 330, 74.
188 A. C. T. van Duin, S. Dasgupta, F. Lorant and W. A. Goddard, J. Phys. Chem. A, 2001, 105, 9396-9409.

189 S. Matera and K. Reuter, Catal. Lett., 2009, 133, 156-159.

190 D. G. Vlachos, AIChE J., 2012, 58, 1314-1325.

191 N. Rankovic, C. Chizallet, A. Nicolle, D. Berthout and P. Da Costa, Oil Gas Sci. Technol., 2013, 68, 995-1005.

192 R. F. de Morais, P. Sautet, D. Loffreda and A. A. Franco, Electrochim. Acta, 2011, 56, 10842-10856.

193 M. Salciccioli, M. Stamatakis, S. Caratzoulas and D. G. Vlachos, Chem. Eng. Sci., 2011, 66, 4319-4355.

194 M. Maestri and K. Reuter, Chem. Eng. Sci., 2012, 74, 296-299.

195 N. Rankovic, C. Chizallet, A. Nicolle and P. Da Costa, Ind. Eng. Chem. Res., 2013, 52, 9086-9098. 